\title{
Combustion Behaviour of Single Pellets of Coal-Wood Mixtures in a Hot Gas Flow Field
}

Chinsung Mock ${ }^{\mathrm{a}}$, Hookyung Lee ${ }^{\mathrm{b}}$, Seuk-Cheun $\mathrm{Choi}^{\mathrm{a}}$, Won Yang ${ }^{\mathrm{a}}$, Sangmin Choi ${ }^{\mathrm{c}}$, Vasilije Manovic*

a Thermochemical Energy System Group, Korea Institute of Industrial Technology, 89 Yangdaegiro-gil, Ipjang-myeon, Seobuk-gu, Cheonan, Chungnam 31056, South Korea

${ }^{\mathrm{b}}$ Corporate R\&D Institute, Doosan Heavy Industries \& Construction Co. Ltd, Youngin 16858, Korea. Tel.: +82-31-326-2210

${ }^{\mathrm{c}}$ Department of Mechanical Engineering, Korea Advanced Institute of Science and Technology (KAIST), Daehak-ro, Yuseong-gu, Daejeon, South Korea

* Centre for Combustion and Carbon Capture and Storage, Cranfield University, Cranfield, Bedfordshire MK43 0AL, UK

*Corresponding author.

E-mail address: v.manovic@cranfield.ac.uk (V. Manovic). 


\begin{abstract}
This experimental study explores the burning characteristics of single pellets made of wood and coal mixtures for co-firing. Three types of pellets were prepared with different wood to coal ratios (100:0, 80:20\% and 50:50\%). Experiments were carried out in a laboratory reactor at rapid heating rates and under oxygen concentrations between $10 \%$ and $40 \%$. To investigate their combustion behaviour, a single pellet was suspended on a wire injected into a hot gas stream at $1340 \mathrm{~K}$, and flame and char combustion were recorded through an observation window by means of a high-resolution $(4 \mathrm{~K})$ camera. The sequential combustion time, volatile flame characteristics and mass reduction rate were obtained over a time profile by carefully controlled particle injection. The results demonstrated that the char combustion time increased significantly compared with the volatile combustion time, which only varied a little, when the pellets contained coal in the mixture. Partially detached flames were also predominantly observed on pure biomass pellets at oxygen concentrations between $21 \%$ and $40 \%$. During the homogeneous combustion period, the cross-sectional area of a pellet shrunk by $26.3 \%-37.5 \%$, depending on the type of pellet.
\end{abstract}




\section{Introduction}

Biomass is a carbon-neutral fuel that replaces traditional fossil fuels and increases the share of renewable energy available to meet the rising electricity demand. ${ }^{1,2}$ Several economic benefits, such as fuel price stabilisation and low capital costs, are also expected. ${ }^{3,4}$ Biomass contains highly volatile matter and low levels of fixed carbon with different organic composition (lignin, hemicellulose and cellulose), resulting in rapid devolatilisation, short burning times, a low sooty flame and flame instability. ${ }^{5-7}$ Currently, the efficiency of biomass power generation is lower $(16 \%-25 \%)$ than that of coal-fired plants $(33 \%-38 \%)^{8}$, owing to the radiative heat transfer energy during the formation of soot. ${ }^{9,10}$ Consequently, a fundamental understanding of the behaviour of biomass combustion plays an important role in furnace operation and in the design of furnaces.

Co-firing biomass with coal can be a feasible option to increase flame stability and give longer combustion times. Several studies of co-firing have been performed, generally to understand its environmental and economic benefits. ${ }^{11-13}$ Studies on thermal decomposition, flue gas emission and flame structure have also been reported. ${ }^{14-17}$ Mock et al. ${ }^{17}$ reported the combustion characteristics of a pulverised single particle with coal and wood mixtures. They showed that the apparent flame size and intensity increased by increasing the coal-blending ratio.

Biomass pelletisation is also one solution to improve fuel quality, energy density, transportation and storage. ${ }^{18,19}$ Solid pellets can be burned in relatively large-sized grate -fired boilers or a

fluidised bed furnace. ${ }^{20-23}$ Shan et al. ${ }^{22}$ examined the ignition and combustion modes of biomass pellets under $\mathrm{N}_{2} / \mathrm{O}_{2}$ and $\mathrm{CO}_{2} / \mathrm{O}_{2}$ environments. The hetero-homogeneous combustion was observed under $50 \%$ oxygen concentration, and the length of the flame became shorter when the oxygen concentration increased. Isemin et al. ${ }^{23}$ investigated the calorific value of 
sludge pellets blended with coal, and their carbon dioxide emission. Previous researchers introduced the biomass pellet blended with coal to investigate the combustion feasibility. ${ }^{24,25}$

Fundamental studies on co-firing characteristics are mainly based on thermogravimetric analysis. ${ }^{26-28}$ The method is limited to explain combustion characteristics, including ignition time, homogeneous and heterogeneous combustion, and physical changes in volatile flames and char particles. A number of experiments were carried out on the combustion of single biomass particles around $1 \mathrm{~mm}$ in size. ${ }^{29-31}$ Single pellets of wood and coal mixtures have not been investigated for sequential co-combustion processes or for burning characteristics at rapid heating rates.

In this paper, an experimental investigation was carried out on the impact of single biomass pellets with coal blends for co-firing. Their combustion behaviours were analysed by direct observation over time. To understand any quantitative differences, 20:80\%, 50:50\% and 0:100\% coal-wood pellets were burned under well-controlled conditions. Images of the burning pellets presented the change in flame luminosity, flame size and char reduction from apparent ignition to char extinction. The results, obtained from the images of the burning pellets, provided sufficient detail of the flame characteristics and combustion times, and further understanding the co-firing characteristics via a modelling description of the pellet combustion would be helpful. 


\section{Experimental Section}

\subsection{Single Pellets of Biomass and Coal Mixtures}

Three different types of pellets, 100:0\%, 80:20\% and 50:50\% wood-subbituminous coal, were prepared. The biomass pellets with coal (Adaro) particle mixtures were made by the pelletisation process introduced by Mock. ${ }^{32}$ Before pelletisation, milling and mixing of the two solid fuels were carried out sequentially. To bond the two different materials, $2 \mathrm{~kg}$ of water per $1 \mathrm{~m}^{2}$ of particles were added as an adhesive source. The particle lengths were 5,10 and $15 \mathrm{~mm}$, and their length-to-diameter ratio (L/D) was 1 to 3, as shown in Table 1 . The weight of the prepared pellet particles were 40,27 and $13 \mathrm{mg}$, the difference in the size of particles of the same weight was small, and it did not noticeably affect their combustion behavior.

Spherical- and cylindrical-shaped particles were prepared to study the role of shape on ignition, overlap combustion and burning time. Proximate and ultimate analyses were obtained on an as-received basis using a TGA-701, a TruSpec elemental analyser and AC600 calorimeter, as shown in Table 2. The results showed that the pure biomass pellet contained the highest mass fraction of volatile matter (81.5\%), compared with the 20:80 and 50:50\% blended pellets, whereas the $50: 50 \%$ pellet had the highest nitrogen content $(0.9 \%)$ because of the high coal blends. 
Table 1. Physical properties of the pellets

\begin{tabular}{|c|c|c|c|}
\hline Name & Mixing rate & Weight, mg (L/D) & Shape \\
\hline \multirow{4}{*}{ Pelletised } & \multirow{4}{*}{$100 \%$} & $40(3)$ & \multirow{2}{*}{ Cylindrical } \\
\hline & & $27(2)$ & \\
\hline & & \multirow{2}{*}{$13(1)$} & Cylindrical \\
\hline & & & Spherical \\
\hline \multirow{2}{*}{ Pelletised } & \multirow{4}{*}{$80: 20 \%$} & $40(3)$ & \multirow{2}{*}{ Cylindrical } \\
\hline & & $27(2)$ & \\
\hline \multirow{2}{*}{ wood-coal } & & \multirow{2}{*}{$13(1)$} & Cylindrical \\
\hline & & & Spherical \\
\hline \multirow{4}{*}{ Pelletised } & \multirow{4}{*}{$50: 50 \%$} & $40(3)$ & \multirow{2}{*}{ Cylindrical } \\
\hline & & $27(2)$ & \\
\hline & & \multirow{2}{*}{$13(1)$} & Cylindrical \\
\hline & & & Spherical \\
\hline
\end{tabular}

Table 2. Proximate and ultimate analysis of the three types of pellets

\begin{tabular}{|c|c|c|c|c|c|c|c|c|c|c|}
\hline \multirow[t]{2}{*}{ Sample } & \multicolumn{4}{|c|}{$\begin{array}{l}\text { Proximate analysis } \\
\text { (wt.\% ar) }{ }^{1}\end{array}$} & \multicolumn{5}{|c|}{$\begin{array}{l}\text { Ultimate analysis } \\
\text { (wt. } \% \text { daf) }^{2}\end{array}$} & \multirow{2}{*}{$\begin{array}{c}\mathrm{LHV}^{3} \\
(\mathrm{MJ} / \mathrm{kg})\end{array}$} \\
\hline & V.M & F.C & Ash & M & $\mathrm{C}$ & $\mathrm{H}$ & $\mathrm{O}$ & $\mathrm{N}$ & $\mathrm{S}$ & \\
\hline Wood & 81.5 & 9.7 & 0.1 & 8.5 & 48.5 & 6.5 & 43.2 & 0.2 & 0.1 & 18.28 \\
\hline Wood-coal $(80: 20)$ & 68.7 & 18.4 & 1.25 & 11.7 & 52.3 & 6.4 & 35.4 & 0.4 & 0.1 & 19.83 \\
\hline Wood-coal (50:50) & 57.0 & 29.5 & 0.56 & 13.0 & 58.6 & 6.2 & 28.1 & 0.6 & 0.1 & 20.82 \\
\hline
\end{tabular}

${ }^{1}$ as received, ${ }^{2}$ dry, ash free, ${ }^{3}$ lower heating value

\subsection{Experimental Set-up for Rapid Heating Rates}

The study was performed in a laboratory-scale entrained flow reactor with a fitted measurement system and an observation device, as shown in Fig. 1. The reactor consists of a rectangular 
quartz tube for the burning pellet with an optical window, a honeycomb burner, a guard heater and a well-controlled particle feeder. The rectangular quartz tube is $45(\mathrm{~L}) \mathrm{mm} \times 45(\mathrm{~W}) \mathrm{mm}$ $\times 500(\mathrm{H}) \mathrm{mm}$. The honeycomb burner is positioned at the bottom of the quartz tube to generate an upward-flowing hot gas stream. To minimise the temperature drop, the guard heater shields the quartz outer wall. The well-controlled particle feeder is installed to insert a pellet systematically into the hot gas stream. The feeder includes a linear-motor-driven pump, a controller, a ceramic injector with a wire, and an insulation tube. The injection speed can be controlled by the linear pump in $1 \mathrm{~s}$ intervals. The ceramic insulation tube protects the possibility of moisture evaporation from the particle. The tungsten wire $(0.3 \mathrm{t})$ is used to suspend a pellet in the hot gas flow.

The measurement of pellet weight during the combustion process in the entrained flow reactor is illustrated in Fig.1 (b). The equipment used is comprised of a water vessel, a hot plate and an electronic scale to record the pellet weight after each test. The following procedure was used: (i) the burning pellet was ejected every 2 seconds, (ii) the burning particle was introduced into a water vessel immediately after ejection, and (iii) the moisture content was eliminated by placing the pellet on a hot plate at $150^{\circ} \mathrm{C}$ until it no longer changing weight. Finally, the weight of dry particle was measured by means of an electronic scale.

A commercial camera (Nikon J5) with a micro lens (Nikon Micro-NIKKOR 105mm f/2.8) was used for direct observation. The observation height (maximum $100 \mathrm{~mm}$ ) was adjusted for the lens. For quantitative and qualitative analysis, the sequential combustion was recorded at $4 \mathrm{~K}$ resolution. During pellet combustion, a high-speed camera is not necessary, because the burning time took a few min. To maintain an identical background, the photographs were taken in a dark room, and a light-emitting diode backlight with uniform luminescence was installed at the rear of the observation window. 
Observation of a burning pellet

1. Start recording the observation window

2. Insert a pellet into the hot gas stream in $1 \mathrm{~s}$

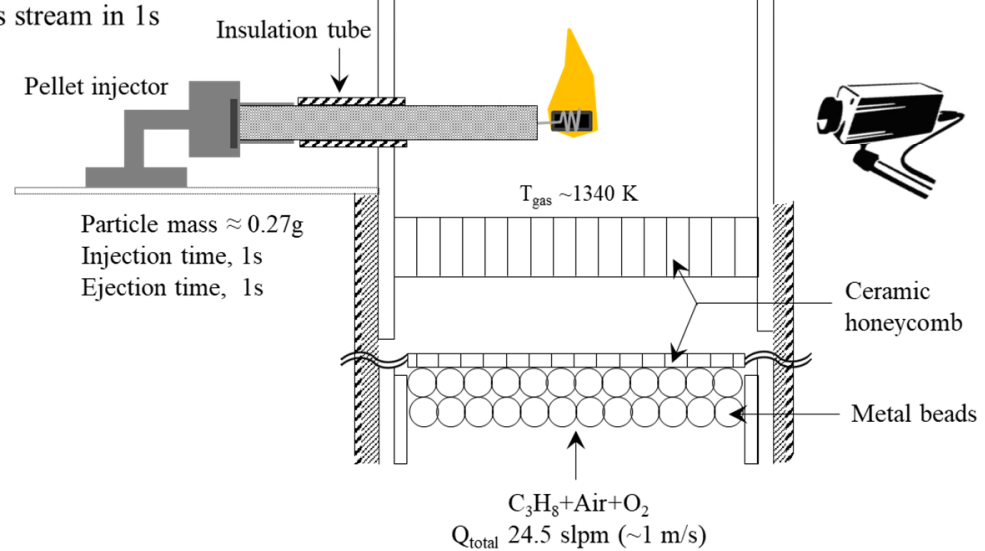

(a)

\begin{abstract}
Measurement of a pellet weight
1. Quenching the flaming pellet in the water vessel every $2 \mathrm{~s}$

2. Drying the wetted pellet on the hot plate

3. Measuring the dried pellet on the scale
\end{abstract}

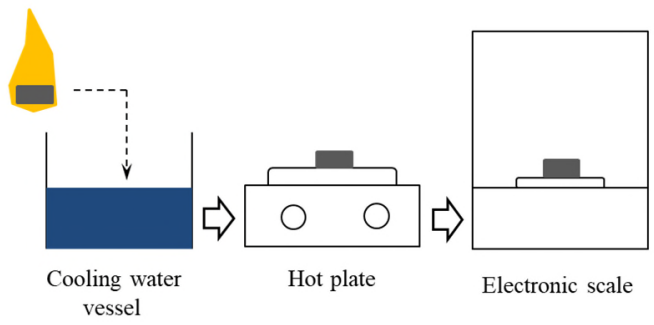

(b)

Fig. 1. Schematic diagram of the laboratory-scale entrained flow reactor using the wire method for single-pellet combustion: (a) Observation of a burning pellet, (b) Measurement of a pellet weight. This shows the process of direct observation and measurement of a single pellet during combustion and explains how the single pellet is injected into the hot gas flow. 


\subsection{Environmental Conditions}

A range of gases, such as $\mathrm{C}_{3} \mathrm{H}_{8}, \mathrm{O}_{2}$ and air, were supplied to the burner as a surrounding hot gas stream. The post-combustion gases contained $\mathrm{N}_{2}(43.27 \%-73.27 \%), \mathrm{O}_{2}(10 \%-40 \%), \mathrm{H}_{2} \mathrm{O}$ (9.56\%) and $\mathrm{CO}_{2}(7.17 \%)$ depending on the composition of the product gases, as shown in Table 3. The volume fractions of oxygen were controlled from $10 \%$ to $40 \%$ to study the effect of oxygen concentration, whereas the flow rate was kept constant at $25 \mathrm{~L} / \mathrm{min}$ in all the experiments. The honeycomb flow straightener is positioned above the burner to generate a laminar gas flow. The temperature difference in the adiabatic flame between the $10 \%$ and $40 \%$ oxygen concentration samples was approximately $140 \mathrm{~K}$. The post-combustion gas was at 1340 $\mathrm{K}$, after $\sim 1 \mathrm{~m} / \mathrm{s}$, and contained under $21 \%$ oxygen, and the gas temperature profile was reported experimentally from previous work by Mock. ${ }^{33}$ The high temperature and rapid heating rate $\left(10^{4}-10^{5} \mathrm{~K} / \mathrm{s}\right)$ allow the suspended single particle to ignite within a few $\mathrm{s}$ after injection.

Table 3. Burner inlet flow rates and the equilibrium composition of the combustion gases

\begin{tabular}{|c|c|c|c|c|}
\hline \multicolumn{5}{|c|}{ Burner gas input $[\mathrm{L} / \mathrm{min}]$} \\
\hline $\mathrm{O}_{2}[\%]$ & $\begin{array}{c}\text { Equivalence } \\
\text { ratio }\end{array}$ & $\mathrm{C}_{3} \mathrm{H}_{8}$ & Air & $\mathrm{O}_{2}$ \\
\hline 10 & 0.54 & & 23.38 & 0.62 \\
\hline 21 & 0.36 & \multirow{2}{*}{0.6} & 19.79 & 4.11 \\
\hline 30 & 0.28 & & 16.93 & 6.97 \\
\hline 40 & 0.23 & & 13.75 & 10.15 \\
\hline
\end{tabular}




\begin{tabular}{|c|c|c|c|c|}
\hline \multicolumn{5}{|c|}{ Equilibrium post-flame (mole fraction) } \\
\cline { 1 - 3 } $\mathrm{O}_{2}[\%]$ & $\mathrm{XN}_{2}$ & $\mathrm{XO}_{2}$ & $\mathrm{X}_{2} \mathrm{O}$ & $\mathrm{X}_{2}$ \\
\hline 10 & 73.27 & 10 & & \\
\cline { 1 - 2 } 21 & 62.27 & 21 & \multirow{2}{*}{9.56} & 7.17 \\
\hline 30 & 53.27 & 30 & & \\
\hline 40 & 43.27 & 40 & & \\
\hline
\end{tabular}

\subsection{Characterisation of the Thermal Decomposition of Biomass}

Biomass consists of starch, triglycerides and lignocellulose, and coal contains hemicellulose, cellulose and lignin. The lignocellulosic materials have significant thermal decomposition as a fuel, whereas the other organic components have a negligible impact on thermal decomposition. The different physical structure and chemical composition affect the characteristics of physical degradation, the gas eruption profile and mass reduction. There are a number of studies on the thermal decomposition behaviours of hemicellulose, cellulose and lignin. Yan et al. ${ }^{34}$ reported that hemicellulose, which has a less stable structure, starts thermal degradation below $473 \mathrm{~K}$ and degrades rapidly from $493 \mathrm{~K}$ to $588 \mathrm{~K}$. Cellulose has an even more stable and stronger bond structure because of its long polymer chains, with the thermal decomposition a little higher at 588-673 K. Lignin acts as a binding agent for the lignocellulosic fibres and contains aromatic rings, which results in slow degradation over a wide temperature range, 433-1173 K.

\subsection{Formation of a Volatile Flame and Char Particle}

The distinct features of a volatile flame are determined by fuel species, surrounding gas temperature, and the physical composition, size and shape of the particle. In a hot gas flow, a single pellet is burned rapidly after the release of any volatile matter, when volatile combustion 
starts immediately with the formation of a sooty flame. Fig. 2 shows the different flame and char modes, obtained from pure wood and 50:50 wood-coal pellets. The pure wood pellet has two boundaries of the flame: separate rich and poor incandescent regions. This type of flame is called a partially detached flame, whereas the 50:50 wood-coal pellets have a diffusion flame, which includes the rich incandescent region of the flame. The partially detached flame is associated with the release and oxidation rates of any volatile matter. The oxygen supplied by diffusion cannot be consumed because of the fast eruption of gaseous and solid phases on the solid fuel particle. Nevertheless, the high oxygen diffusion rate detaches the flame sheet from the particle surface and forms a very thin flame, where char combustion occurs at the edge of the particle surface at the beginning of homogeneous combustion. Scattering layers are observed at the beginning of char combustion on the biomass char surface, because the high volume of lignin in the pure biomass pellet can still be degraded after volatile combustion. The three pellets were burned under the same condition to explain the flame characteristics of the different solid fuel mixtures. The resulting images shown in Fig. 3 illustrate the physical changes in the volatile flame at $1340 \mathrm{~K}$ and at oxygen concentrations between $10 \%$ and $40 \%$. The flames of all the pellets appear as long rod-like structures at under $10 \%$ oxygen, where the soot particles coalesce and agglomerate with each other in the vicinity of the pellet surface. The intensities of their flames varied with the mixture ratio, which is attributed to the different volume fraction of soot particles. The jet-like tails were only observed on the biomass pellet with coal particles. 


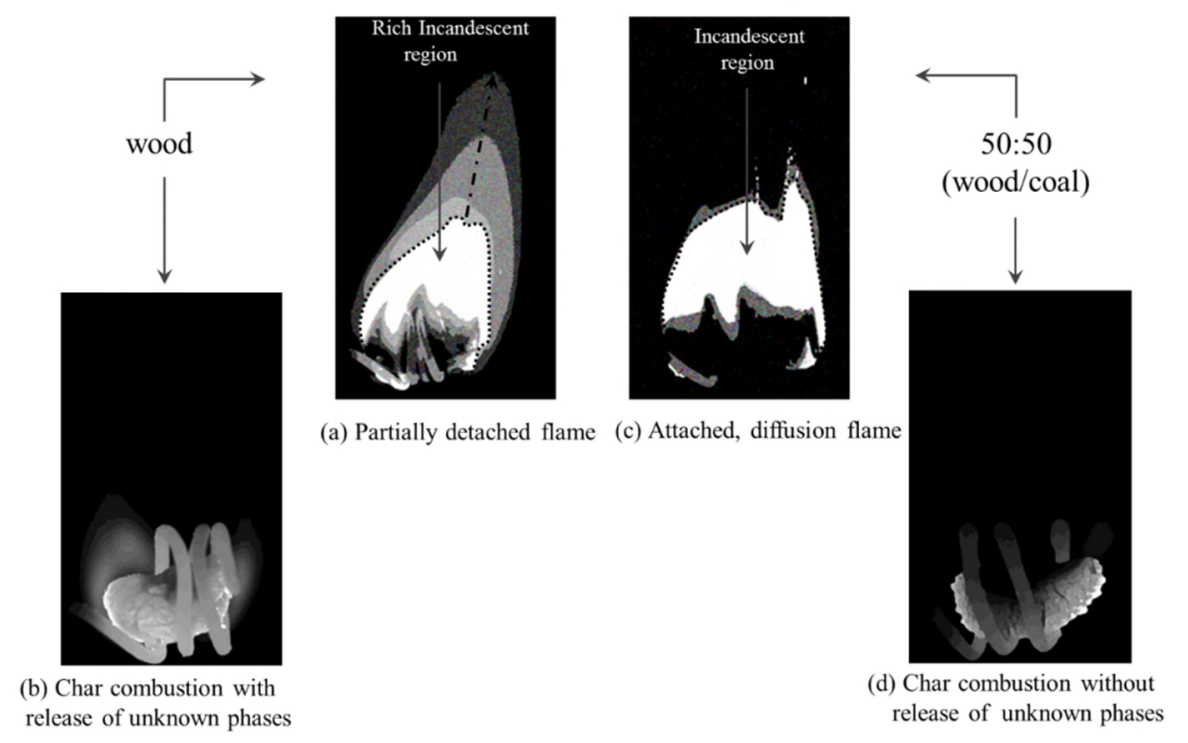

Fig. 2. Greyscale images of two different flames and char modes of wood and 50:50 woodbiomass. The shape and luminosity of the flame depend on the type of solid fuel.

\begin{tabular}{|c|c|c|c|c|}
\hline & $10 \% \mathrm{O}_{2}$ & $21 \% \mathrm{O}_{2}$ & $30 \% \mathrm{O}_{2}$ & $40 \% \mathrm{O}_{2}$ \\
\hline $\begin{array}{l}\text { Wood } \\
(100 \%)\end{array}$ & & & & \\
\hline $\begin{array}{l}\text { Wood-coal } \\
(80: 20 \%)\end{array}$ & & & & \\
\hline $\begin{array}{l}\text { Wood-coal } \\
(50: 50 \%)\end{array}$ & & & & \\
\hline
\end{tabular}

Fig. 3. Soot flames of the three pellets under $10 \%-40 \%$ oxygen concentrations at $1340 \mathrm{~K}$. The images illustrate the physical change in the volatile flame, which is attributed to the coal mixtures and oxygen concentrations. 


\section{Results and Discussion}

\subsection{Thermal Decomposition of Pellets at Slow and Rapid Heating Rates}

The decomposition of the pure biomass pellet was analysed by thermogravimetric (TG) and derivative thermogravimetric (DTG) curves, using TG/DTA 92-18, where the biomass sample was heated at a rate of $20 \mathrm{~K} / \mathrm{min}$. The results gave two curves, as shown in Fig. 4(a). In the TG and DTG curves at a low heating rate, three peaks were plotted during the whole process. The first peak is associated with the evaporation of water content in the particle and occurs at 300$400 \mathrm{~K}$. The second peak occurs at approximately $620 \mathrm{~K}$, when the hemicellulose and cellulose contents undergo high mass reduction. ${ }^{35}$ The last peak is at approximately $750 \mathrm{~K}$ and is attributed to the degradation of lignin..$^{36,37}$ To compare the degradation of biomass at slow and rapid heating rates, the single pellets were burned at $1340 \mathrm{~K}$ in the laboratory entrained flow reactor. Fig. 4(b) shows the mass reduction and the DTG curves of the pure wood pellets under

the rapid heating rates. The overlapping combustion starts after approximately $6.5 \mathrm{~s}$, and the hemicellulose begins to degrade after heating from the bottom. The ignition temperature was assumed to start at $493 \mathrm{~K}$, based on the degradation temperature of hemicellulose (493-588 K). The first peak occurs after 6.5-23 s. In this first period, hemicellulose and cellulose degrade rapidly, and the largest volatile flame can be observed just above this peak owing to the release of the solid phase, such as carbonaceous particles. The second trough occurs at $673 \mathrm{~K}$, where the cellulose breaks down completely, and the volatile flame exists at around $39 \mathrm{~s}$ owing to degradation of the lignin. The graph comparing the slow and rapid heating rates can help to explain burning characteristics such as ignition and burning times. 


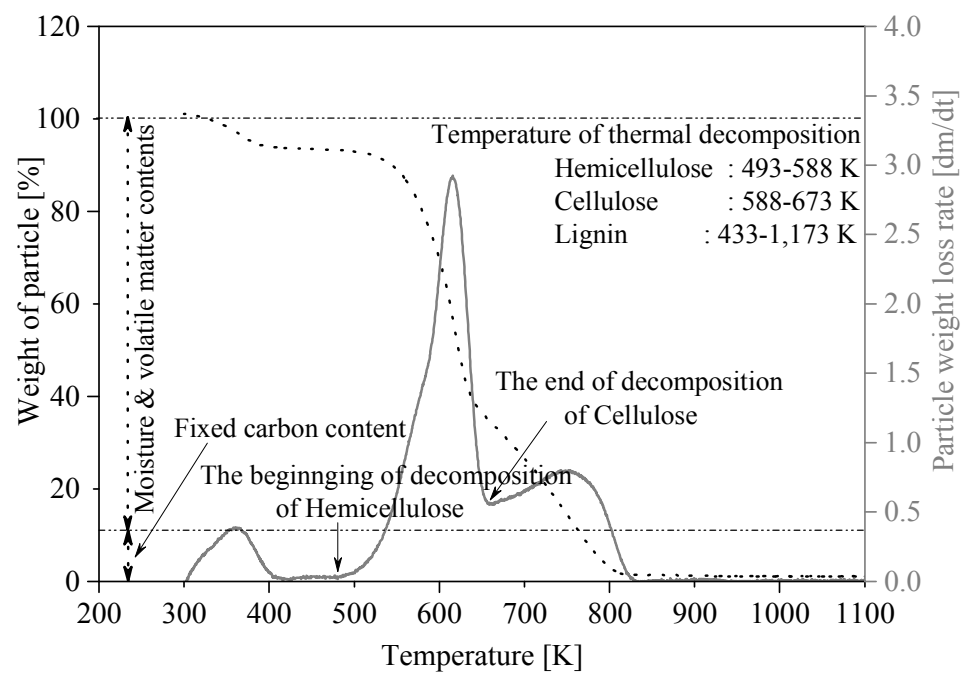

(a)

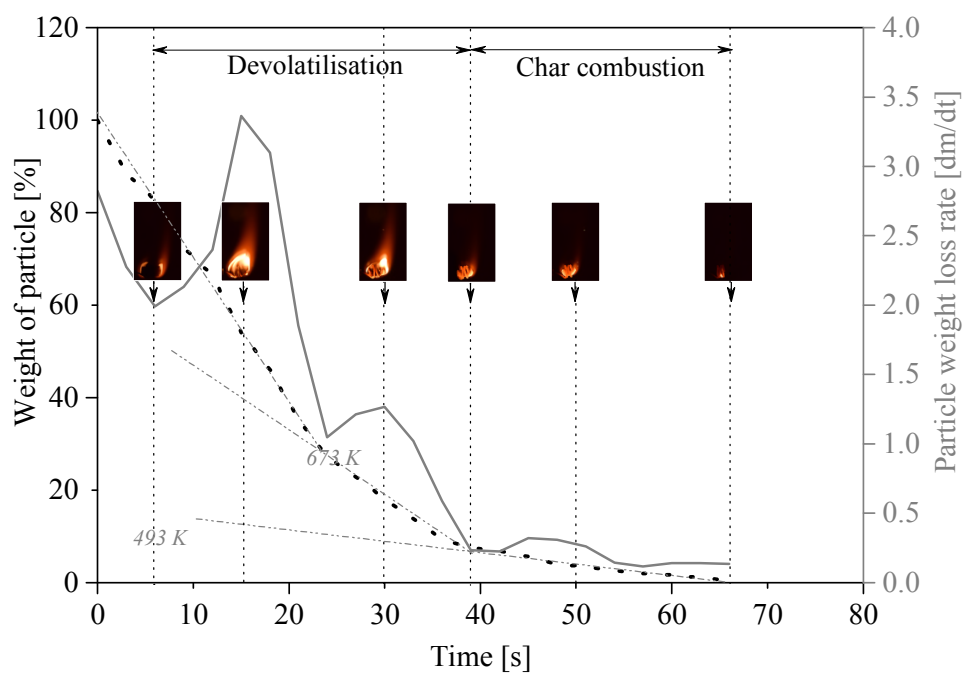

(b)

Fig. 4. Comparative thermal decompositions of a pure wood pellet obtained from thermogravimetric analysis (TGA) and a laboratory entrained flow reactor (EFR) at a heating rate of $20 \mathrm{~K} / \mathrm{min}$ and rapid heating rates, respectively: (a) TG and DTG, obtained from TGA, and (b) TG and DTG, obtained from EFR. Plotted graphs illustrate the distinction of mass 
reduction, associated with volatile and char combustions under slow and rapid heating rates.

The mass reduction of the pellets, suspended on a tungsten wire, was measured every $2 \mathrm{~s}$ under a $21 \%$ oxygen atmosphere and at $1340 \mathrm{~K}$. TG and DTG curves were derived from the particle heat-up $\left(t_{0}=0\right)$ from injection to extinction of char combustion; see Fig. 5. The injection time takes only $1 \mathrm{~s}$ owing to linear -motor-driven pump operation. As shown in Fig. 5(a), the volatile matter and moisture content of wood, wood-coal 80:20\% and wood-coal 50:50\% were roughly $90 \%, 80 \%$ and $70 \%$, respectively, assuming that the curves for mass reduction of fixed carbon and ash are linear. This is in agreement with the proximate analysis as shown in Table 2 . The plotted results show that the increase in fixed carbon, obtained from coal mixtures, increased significantly at burn-out time, whereas the volatile combustion time varied over a small interval because volatile oxidation is fast enough for the erupted volatile matter on the particle surface to burn. Fig. 5(b) shows the peaks of the pellet mass reduction, followed by fluctuations between the three pellets. The first peak is associated with the degradation of hemicellulose and cellulose, where the pure biomass has the highest peak because of the high volume of hemicellulose and cellulose. ${ }^{38}$

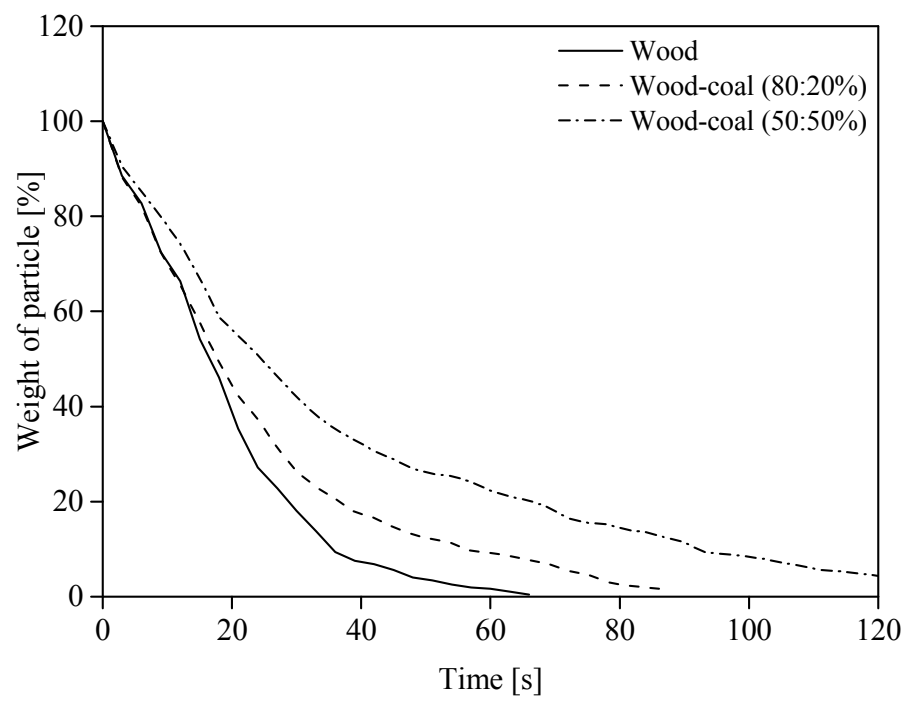


(a)

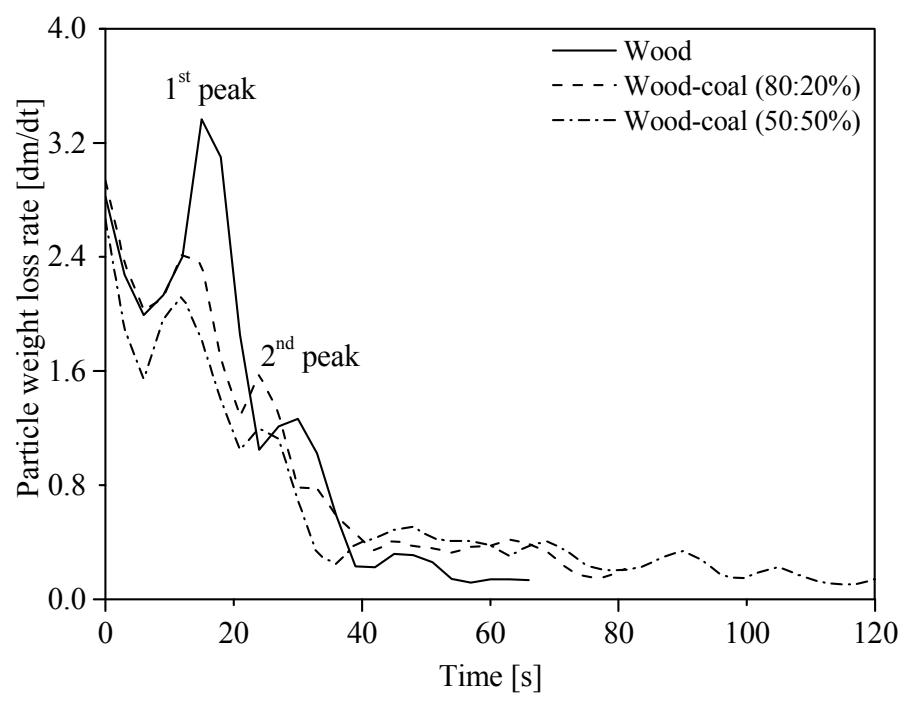

(b)

Fig. 5. Thermal decomposition of wood and the combustion processes of biomass $100 \%$ ), \%, wood-coal 80:20\% and wood-coal 50:50\% pellets under an atmosphere containing $21 \%$ oxygen and at $1340 \mathrm{~K}$ : (a) mass reduction of particles and (b) particle weight loss rate.

\subsection{Observation of Burning Pellets}

\subsubsection{Image of a Burning Particle (0.4 g) under $21 \%$ Oxygen}

The mass of pellet sample for each experiment was $\sim 0.27 \mathrm{~g}$ and contained more than 20 particles. The beginning of volatile combustion takes a few seconds in the large pellets, compared with the ignition time (maximum a few hundred milliseconds) of a pulverised particle, which has a negligible particle temperature gradient. As shown in Fig. 6, char burning was observed at the edge of the pellet in the early combustion stage and developed slowly from the edge during volatile combustion. This was called overlapping combustion and was seen in 
a pulverised particle with an irregular shape under high oxygen concentration ${ }^{39}$. The char temperature increased rapidly after the flame was extinguished following volatile combustion. The burn-out time was variable between the three pellets and was attributed to the difference in the volume fraction of fixed carbon. Interestingly, the soot flame was observed away from the particle surface and had a different intensity and shape in each of the three pellets. A poor incandescent region of the flame from the $100 \%$ biomass pellet was observed from the beginning of the overlapping combustion, whereas the wood-coal 50:50\% pellet appeared to have the brightest flame.

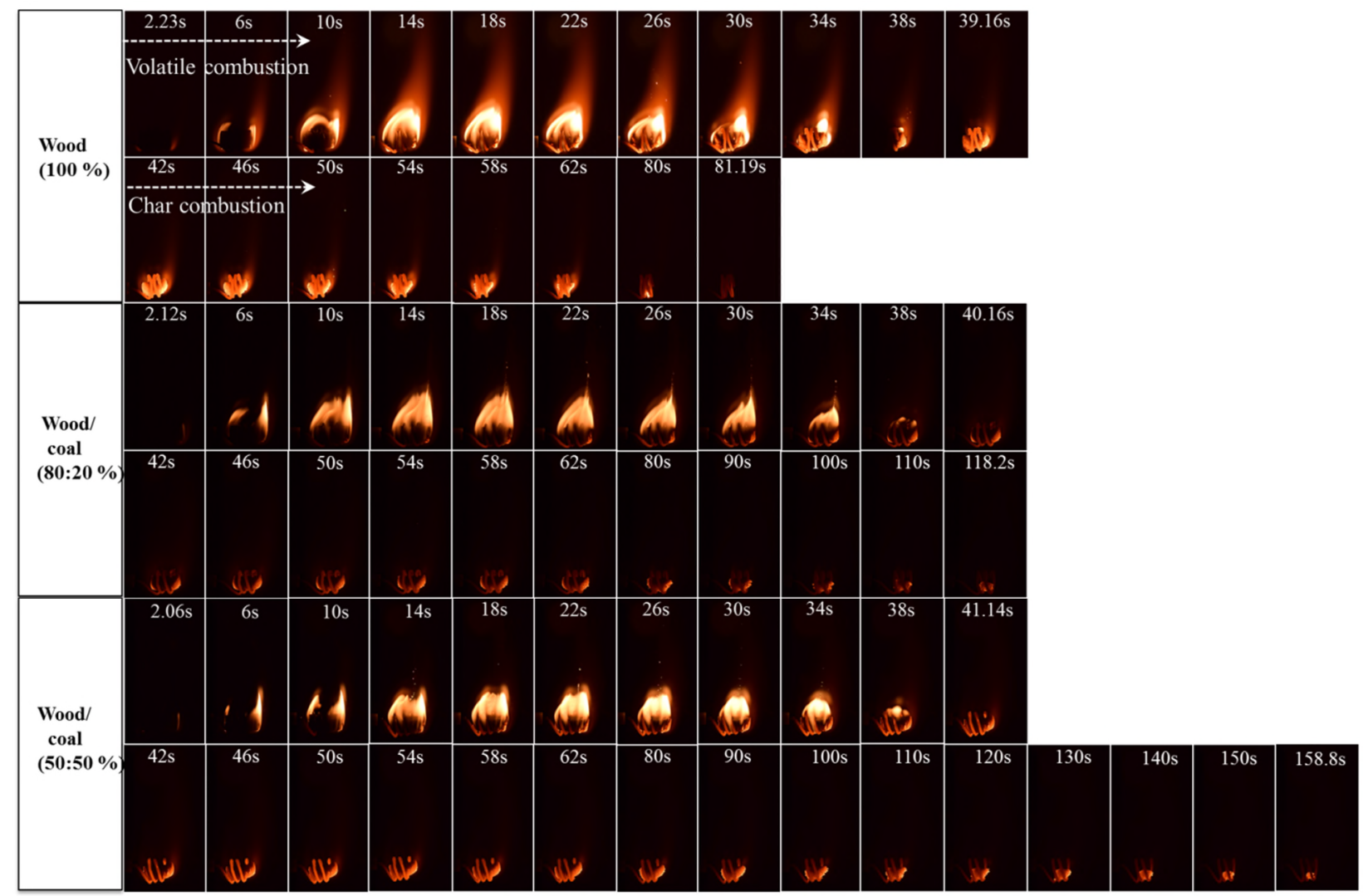

Fig. 6. Photographs of three pelletised particles under $21 \%$ oxygen: (a) a $100 \%$ wood pellet (b) a mixed wood and coal (80:20\%) pellet and (c) a mixed wood and coal (50:50\%) pellet. The figure illustrates the different flame structures and heterogeneous combustion times. 


\subsubsection{Volatile Combustion}

Volatile matter is released with a certain amount of soot particles when the particle ignites on the surface, thereby forming a volatile flame. ${ }^{40,41}$ The physical structure of the flame is determined by the type of fuel, the heating rates and the hot gas temperature. ${ }^{42,43}$ An increase in the oxygen concentration also accelerates the gas-phase combustion, with a thin volatile cloud and a high flame intensity. From these observations of the three pellets, there was no significant difference in the flame size (approximately $110-125 \mathrm{~mm}^{2}$ ). However, the flame colour could be distinguished under $10 \%$ oxygen concentration: it was light yellow for the $100 \%$ wood pellet, moderately dark yellow for the 80:20 wood-coal pellets and very dark yellow for the 50:50 wood/-coal pellet. The dark yellow flames changed to a light yellow relatively thin flame when under a high oxygen concentration. During volatile combustion, a weight loss of the burning pellet is expected, because char oxidation at the edge of the pellets occurs along with volatile oxidation in the pellets. Particle volume shrinkage was observed in the direction of particle mass reduction and varied in moisture evaporation, volatile release and carbon oxidation. Fig. 7 shows the reduction rates of the particle cross-sectional size in the burning pellets under $10 \%$ oxygen concentration: $37.5 \%$ (100\% wood), $32.4 \%$ (80:20 wood-coal) and $26.3 \%$ (50:50 wood-coal).

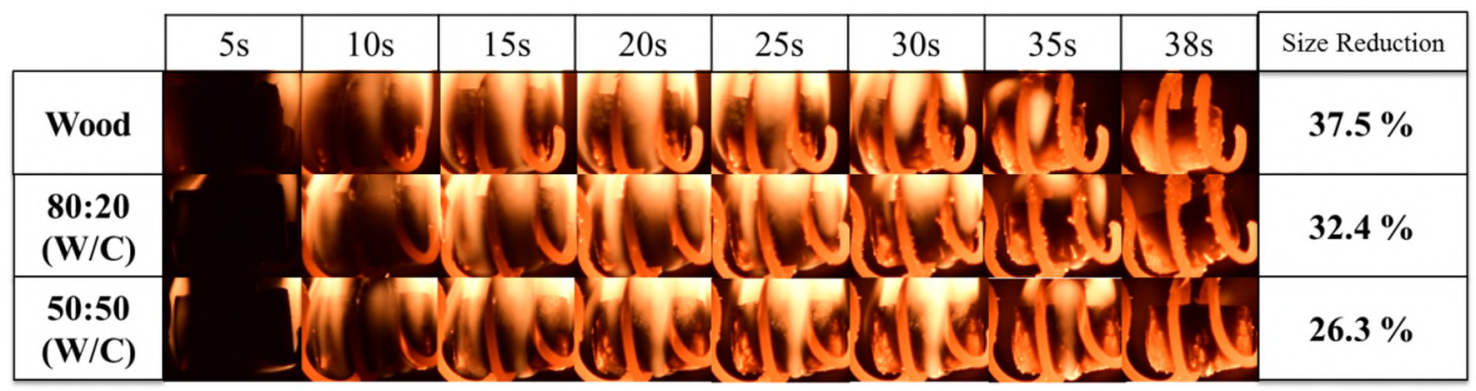

Fig. 7. Images showing the reduction in size during volatile combustion for the $100 \%$ wood, $80: 20 \%$ wood-coal and 50:20\% wood-coal pellets under a 21\% oxygen atmosphere. 


\subsubsection{Char Combustion}

Biomass char particles are highly reactive, compared with the reactivity of coal char. ${ }^{44}$ To compare the char combustion behaviours between the three pellets, the char particles were ejected every 2 seconds after the end of volatile combustion. To prevent any oxidation, the burning char particles were cooled immediately in a cold vessel. Fig. 8(a-d) shows the plots of how the char particle volume changed during the char combustion process. The rapid heating rates caused most of the particles to be at considerably high particle temperatures, but the extent of particle mass loss was different between the three pellets. Particle shrinkage was in the same direction as char particle mass loss, which is in agreement with previous research. ${ }^{45}$ The measurement of particle temperature has not been reported here. On the basis of direct observation, the pure biomass char particle presented a little bright flame among the three pellets, which is associated with its high char reactivity and a more active overlapping combustion during the early stage. Physical deformations, such as melting, bubbles and cracks, were also observed in all three pellets, but a high volume of bubbles occurred in the 80:20 wood-coal and 50:50 wood-coal pellets. 


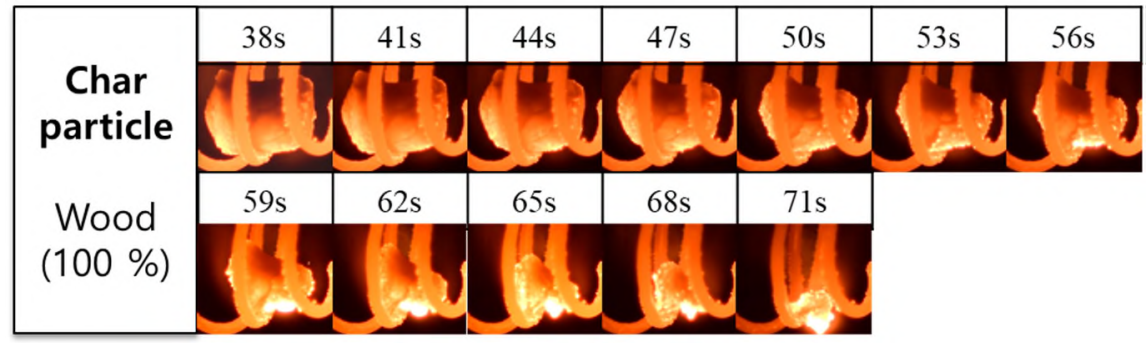

(a)

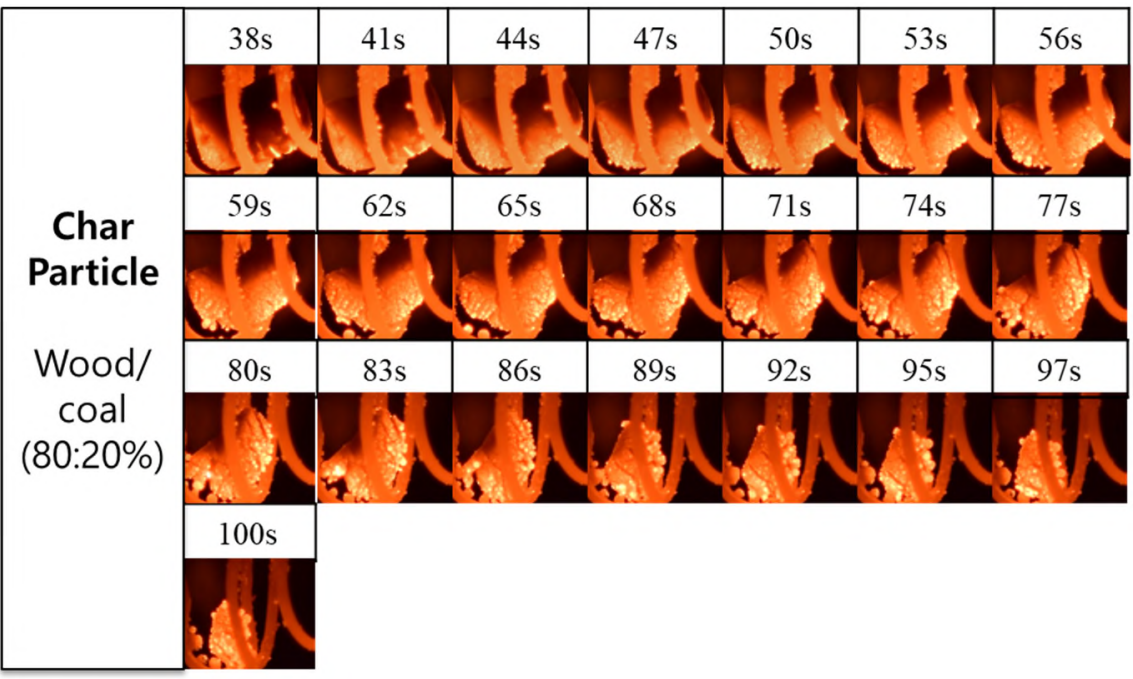

(b)

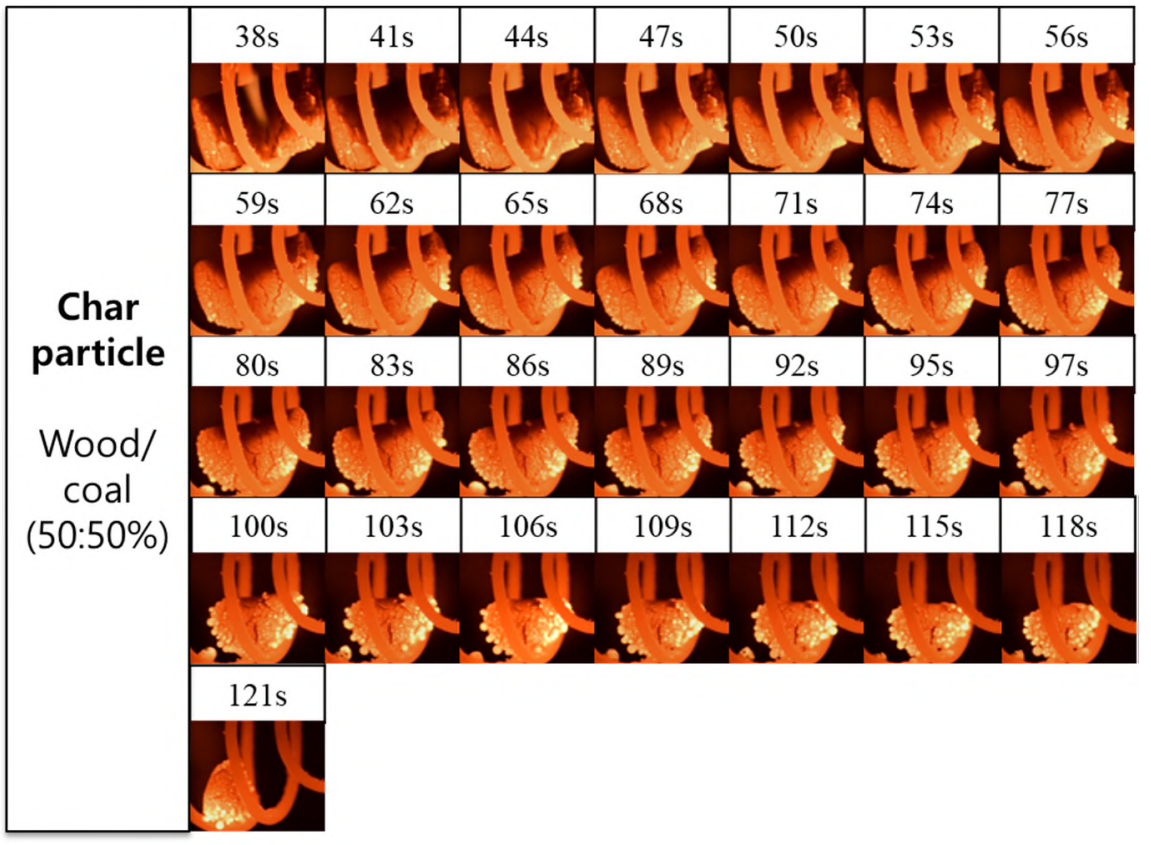

(c) 


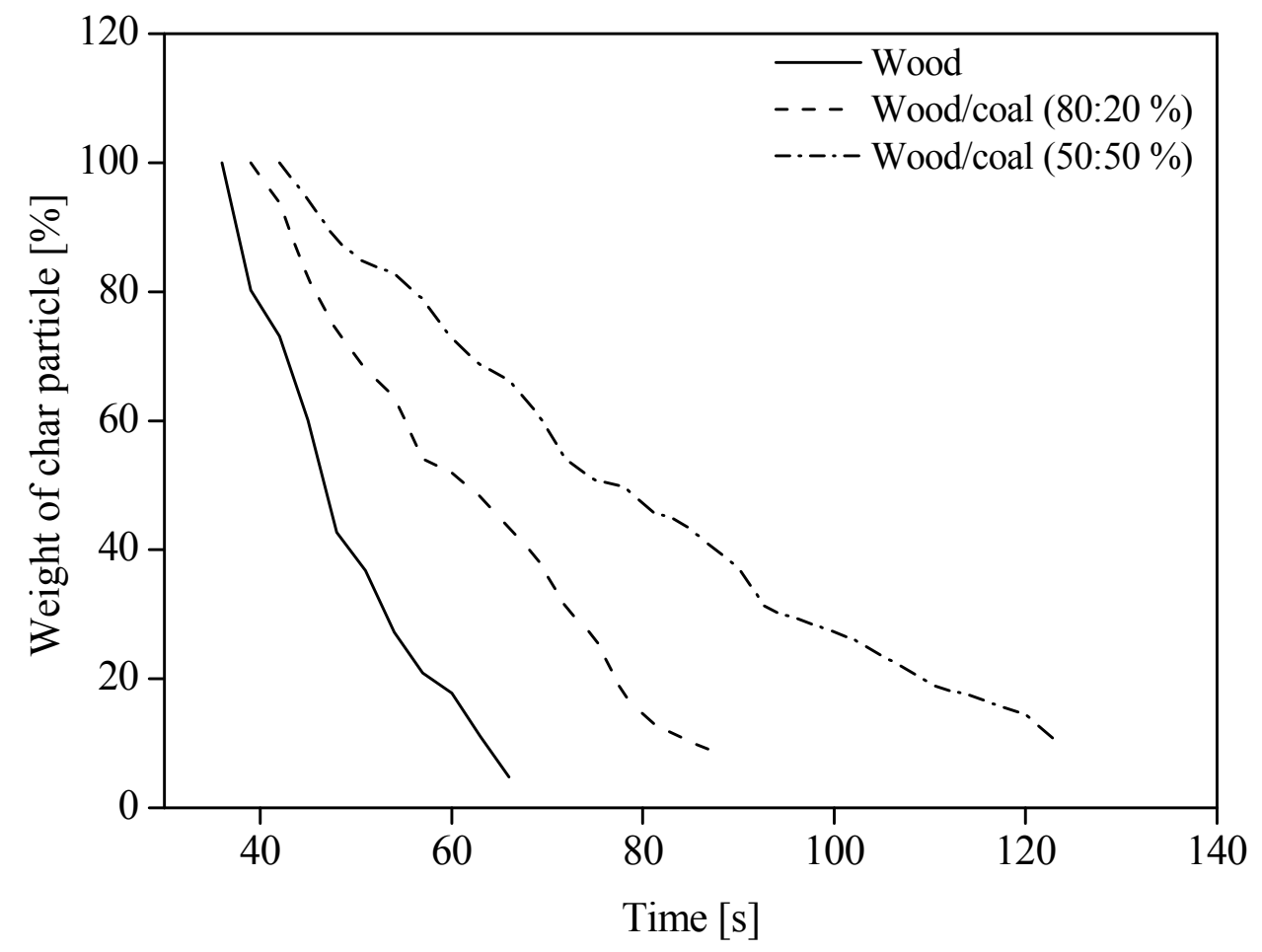

(d)

Fig. 8. Mass reduction of char particles under $21 \%$ oxygen atmosphere. An image $(a-c)$ show physical deformations such as swelling, melting and bubbles of the three char particles: (a) 100\% wood pellet, (b) wood and coal (80:20\%) and (c) wood and coal (50:50\%). (d) Weight loss curves of the three pellets.

\subsection{Combustion Time Profiles}

The gas-phase and solid-phase combustion duration was measured under rapid heating rates and a $21 \%$ oxygen atmosphere. The combustion duration was averaged over 20 particle samples $(0.27 \mathrm{~g})$ to give a quantitative comparison. Fig. 9 illustrates the average volatile combustion and char combustion time for each tested sample containing 20 pellet particles. The standard deviation was calculated to be less than $5 \%$ of the mean values. The plotted graph shows that the duration of the gas-phase combustion of the three pellets was not different, but 
the burn-out time of the solid-phase combustion of the 80:20 wood-coal pellets was over double that of the pure biomass pellets. It should be noted that a moderate period, for so called "overlapping combustion", existed in the early combustion stage, and it was considered as a part of volatile combustion process because of the presence of a flame and it was of a short duration. Consequently, the coal-blending ratio dramatically increases the duration of char combustion owing to the increase in the fixed carbon volume fraction. In fact, the intra-particle temperature appears in large particles where the temperature difference was also induced by particle shape and char reactivity.

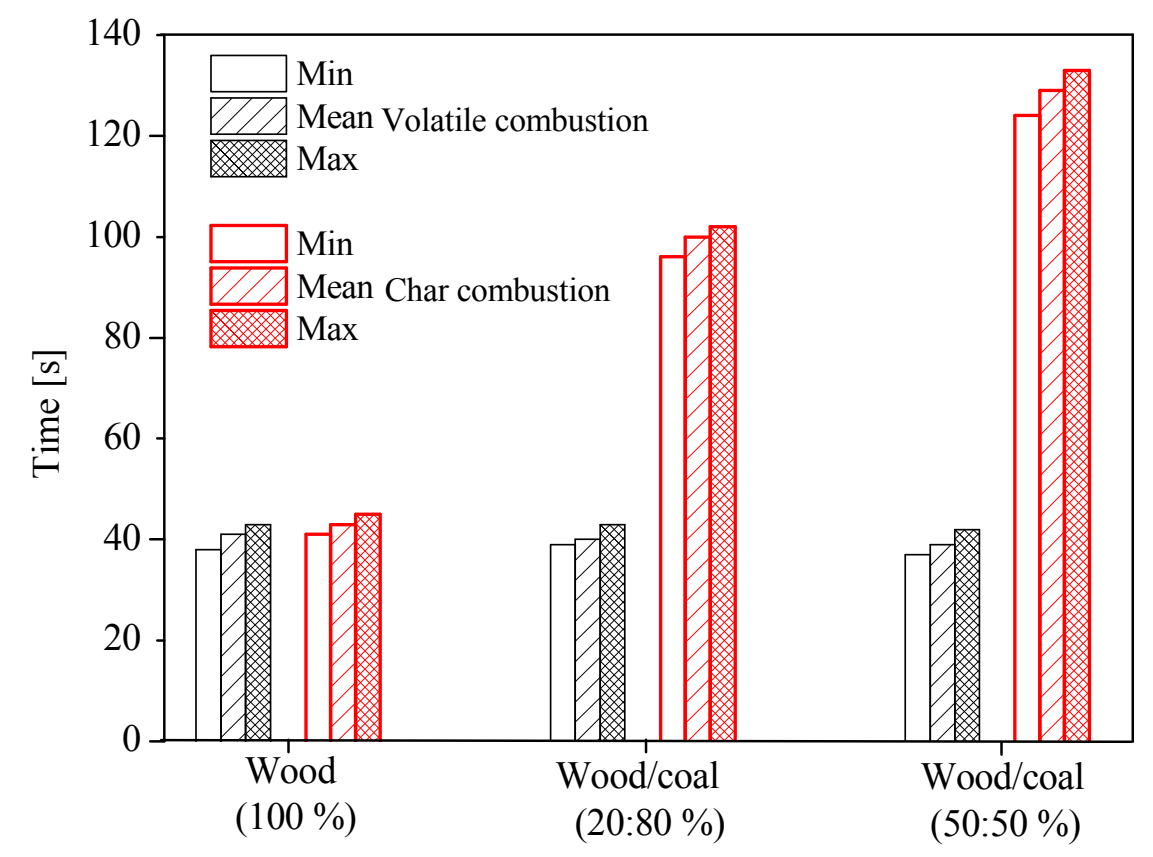

Fig. 9. Average duration of volatile and char combustion for the three pellets $(0.27 \mathrm{~g})$ at $1340 \mathrm{~K}$.

\subsection{Effect of Pellet Size and Shape}

Fig. 10(a) shows the images of the physical changes in the volatile flame of cylindrical pellets of different weights and aspect ratios: $14 \mathrm{~g} \& 1$ (L/D), $27 \mathrm{~g} \& 2$ (L/D), $40 \mathrm{~g} \& 3$ (L/D). All the pellets were burned from the heat-up stage after injection to the end of the volatile combustion 
stage under a 10\% oxygen atmosphere. Particles (14 g) with a spherical shape were also tested to investigate the effect of particle shape. It is accepted that a particle with a large aspect ratio can be heated by external convection and radiation, resulting in an overlapping combustion and a fast conversion rate. ${ }^{30,33}$ The figure also represents the ignition delay from the pellet with the different aspect ratios. The ignition time was faster as the aspect ratio increased in particles with identical diameters, whereas the maximum size of the volatile flame of all the pellets occurred at around $20 \mathrm{~s}$. The fast ignition occurs because of the dramatic increase in temperature at a particle edge where char oxidation and volatile release start simultaneously on the particle surface. This tendency is also clearly observed in increased particle sizes and in the cylindrical shape. These results indicate that the volatile flames have an elongated shape with yellow luminosity and a jet-like long tail. ${ }^{46}$ The long tails are not immediately burned and are oxidised far from the flame cloud when large pellets were burned, which are obviously affected by their temperatures. The full structure of the tail was not observed in the images, because the field of observation was limited in the experiment. It appeared that the conical flame might result in a significant soot breakthrough for the long tails. The graphs in Fig. 10(b-d) show the flame area from the images taken for the three particles, 100\% wood, 80:20 wood-coal and 50:50 wood-coal, under a $21 \%$ oxygen atmosphere. For quantitative analysis, the weight of each pellet had a standard deviation less than $1 \%$. The spherical-shaped pellet had a slightly smaller volatile flame area than the cylindrical pellet of identical particle size. There were no significant changes in volatile flame and ignition time, because the particle diameter and aspect ratio are similar between the two different shapes. 


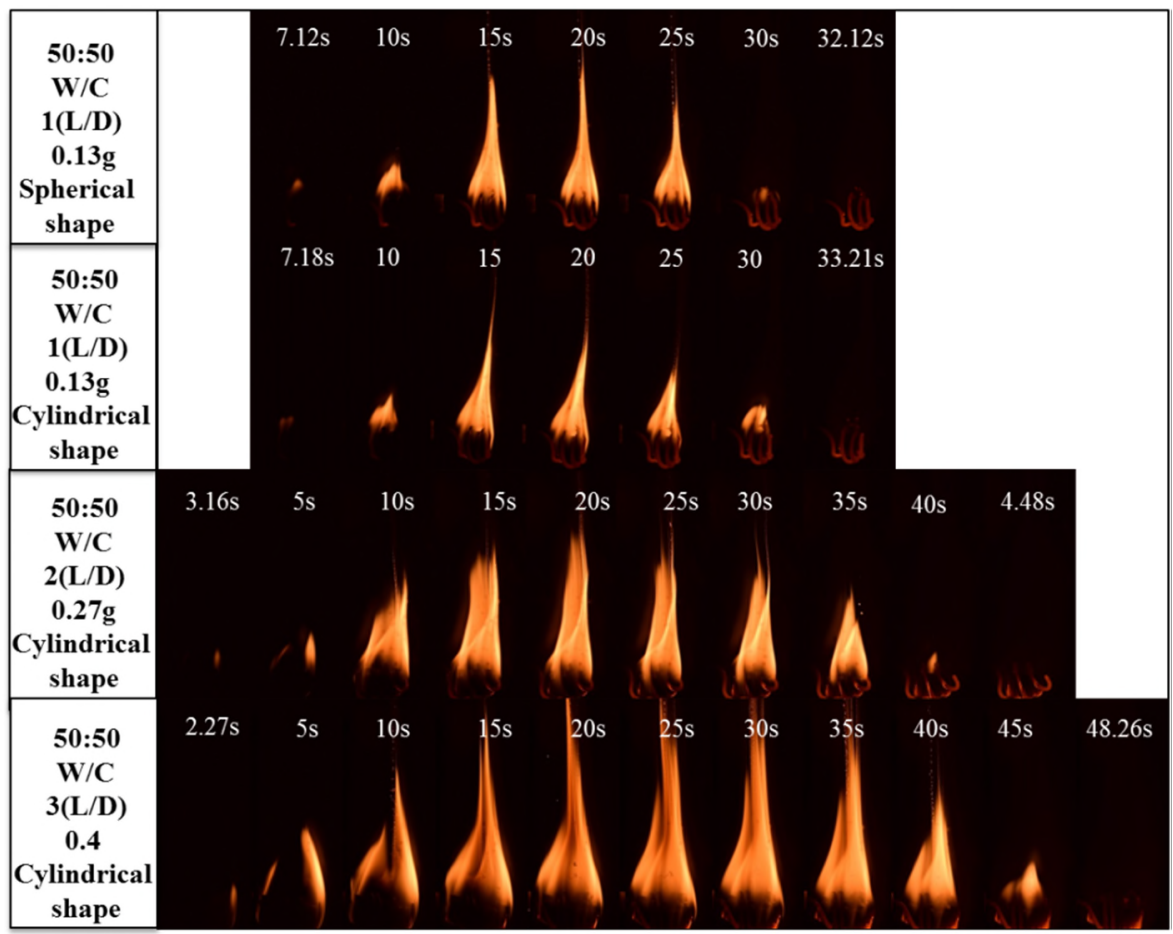

(a)

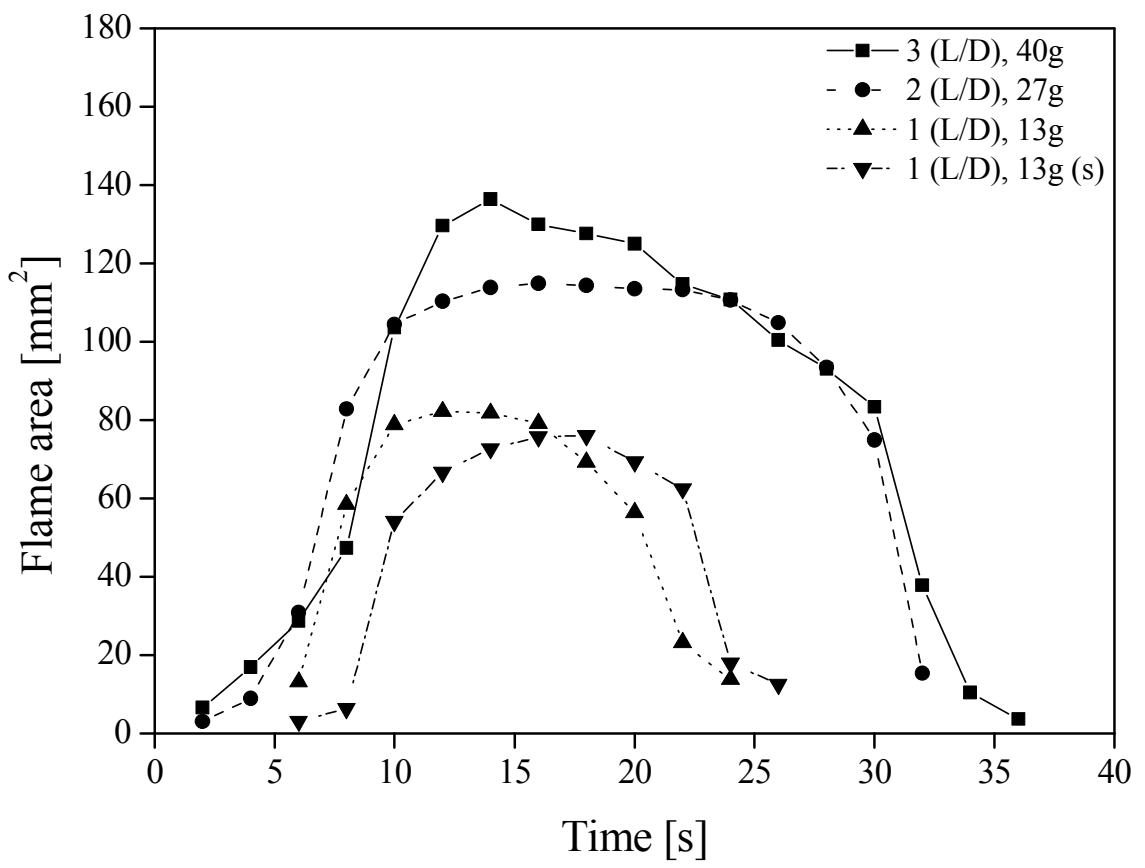

(b) 


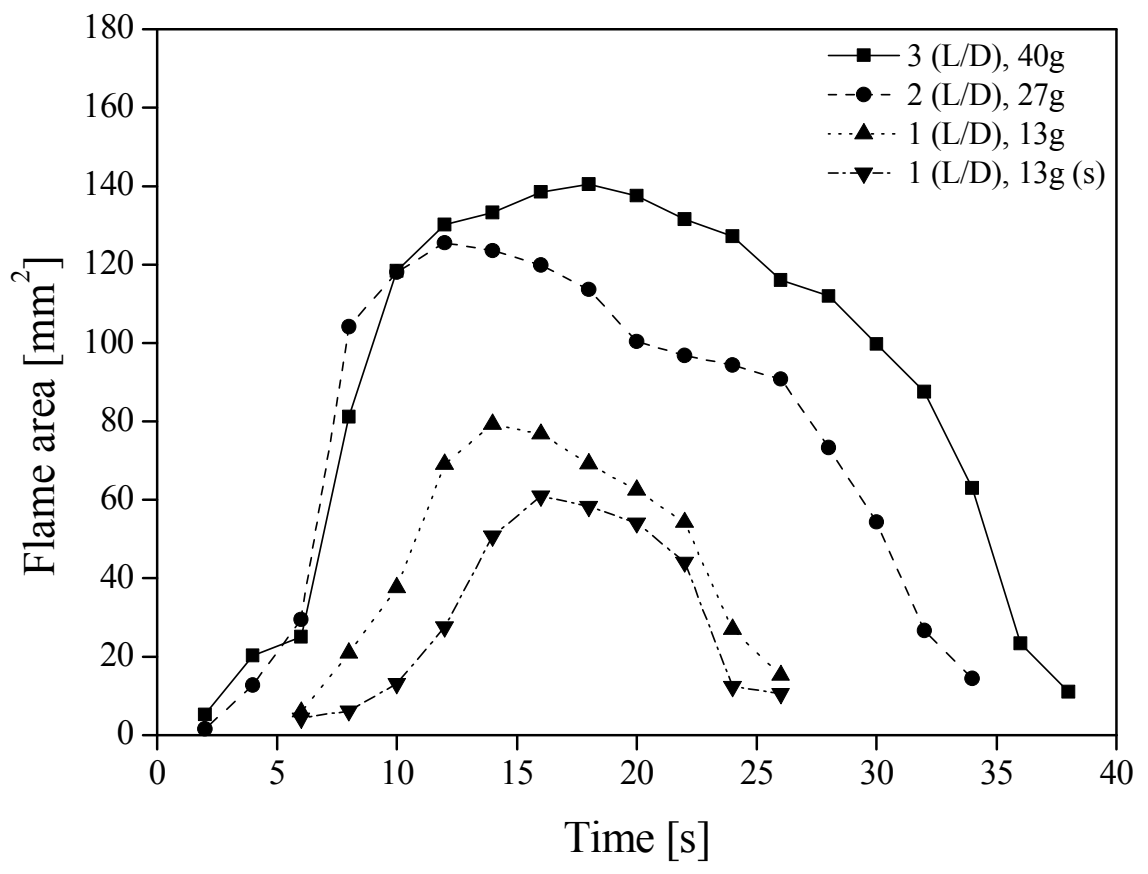

(c)

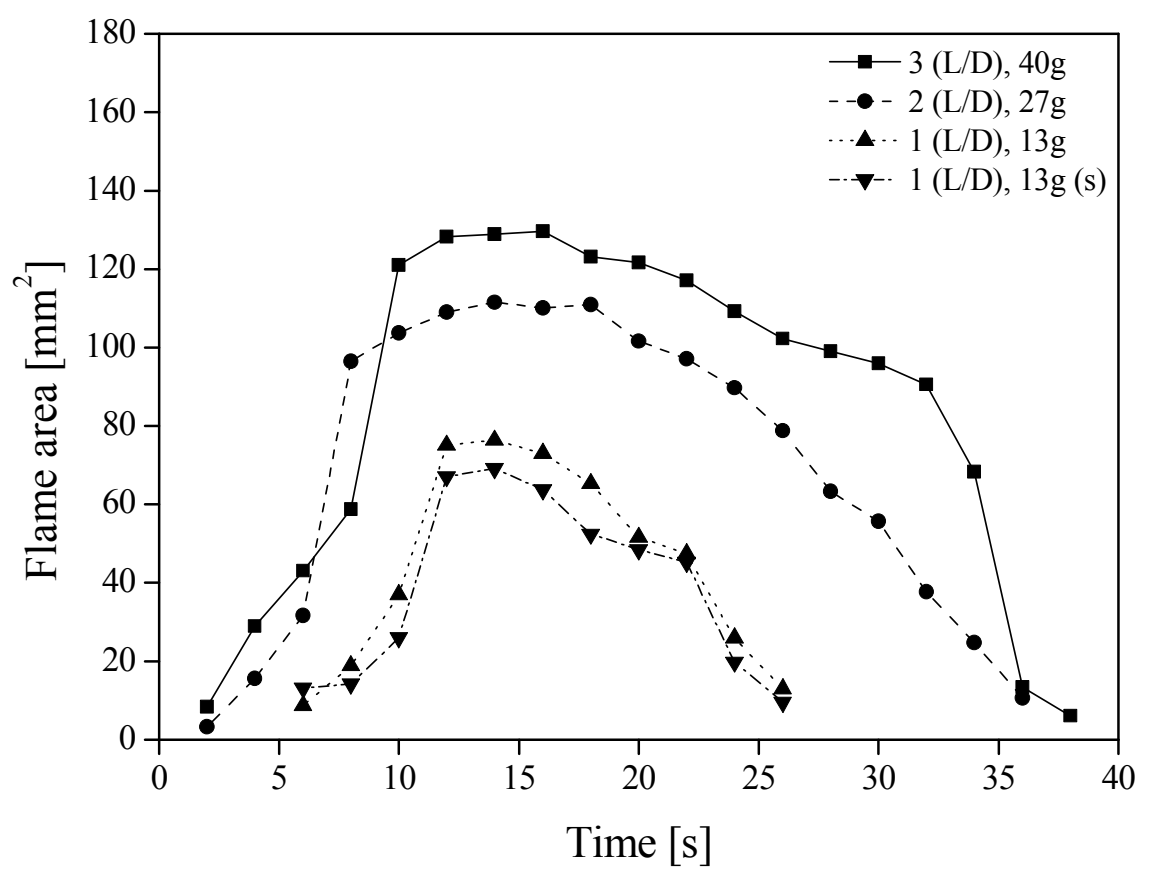

(d)

Fig. 10. Physical changes in the volatile flames between the cylindrical and spherical shapes of pellets: (a) images of volatile flames under a 10\% oxygen atmosphere, (b) flame area of 
100\% wood, (c) flame area of 80:20\% wood-coal and (d) flame area of 50:50\% wood-coal.

\subsection{Effect of Oxygen Concentration on Different Particles}

The soot flame of each pellet ( $0.27 \mathrm{~g}$ ) had comparable burning characteristics such as type of flame, intensity and duration of char combustion under a range of oxygen concentrations, $10 \%-$ 40\%. Fig. 11(a-c) shows the development of the enveloped flame between 100\% wood, 80:20\% wood-coal and 50:50\% wood-coal pellets. The partially detached flame was observed above the surface of the $100 \%$ biomass pellet over $21 \%$ oxygen, whereas pellets of the coal and biomass mixtures had only this type of flame when the oxygen concentration was over $40 \%$.

This phenomenon is attributed to the relatively oxidation of the gaseous and solid phase during combustion. The fuel-rich incandescent flame boundary was shown on all pellets with different luminosity under $10 \%$ oxygen, as they were affected by the soot volume fraction. The ejected pellets were collected after the quenching and drying processes in order to measure the particle mass loss during combustion. Fig. 12 presents the change in the volume of the pellets every 3 seconds, at $10 \%$ oxygen, and shows how they shrunk owing to the release of volatile combustion at the end of char combustion. Dramatic particle mass loss was observed in increased oxygen diffusion rate, especially during char combustion. Particle fragmentation also occurred dominantly at an atmosphere under $40 \%$ oxygen. Pellets with mixtures were prepared for the measurement of their mass reduction over the range of $21 \%-40 \%$ oxygen concentrations.

Fig. 13 illustrates the curves of the particle mass loss of 80:20 biomass-coal and 50:50 biomass-coal pellets by the end of char combustion. The mass reduction for both pellets was 
not significantly different under $40 \%$ oxygen. The difference in their mass reduction between $21 \%$ and $30 \%$ oxygen was clear when the coal-blending ratio increased. Compared with 80:20, the burn-out time of 50:50 increased by about 40 seconds, because of the increase in the fixed carbon volume fraction.

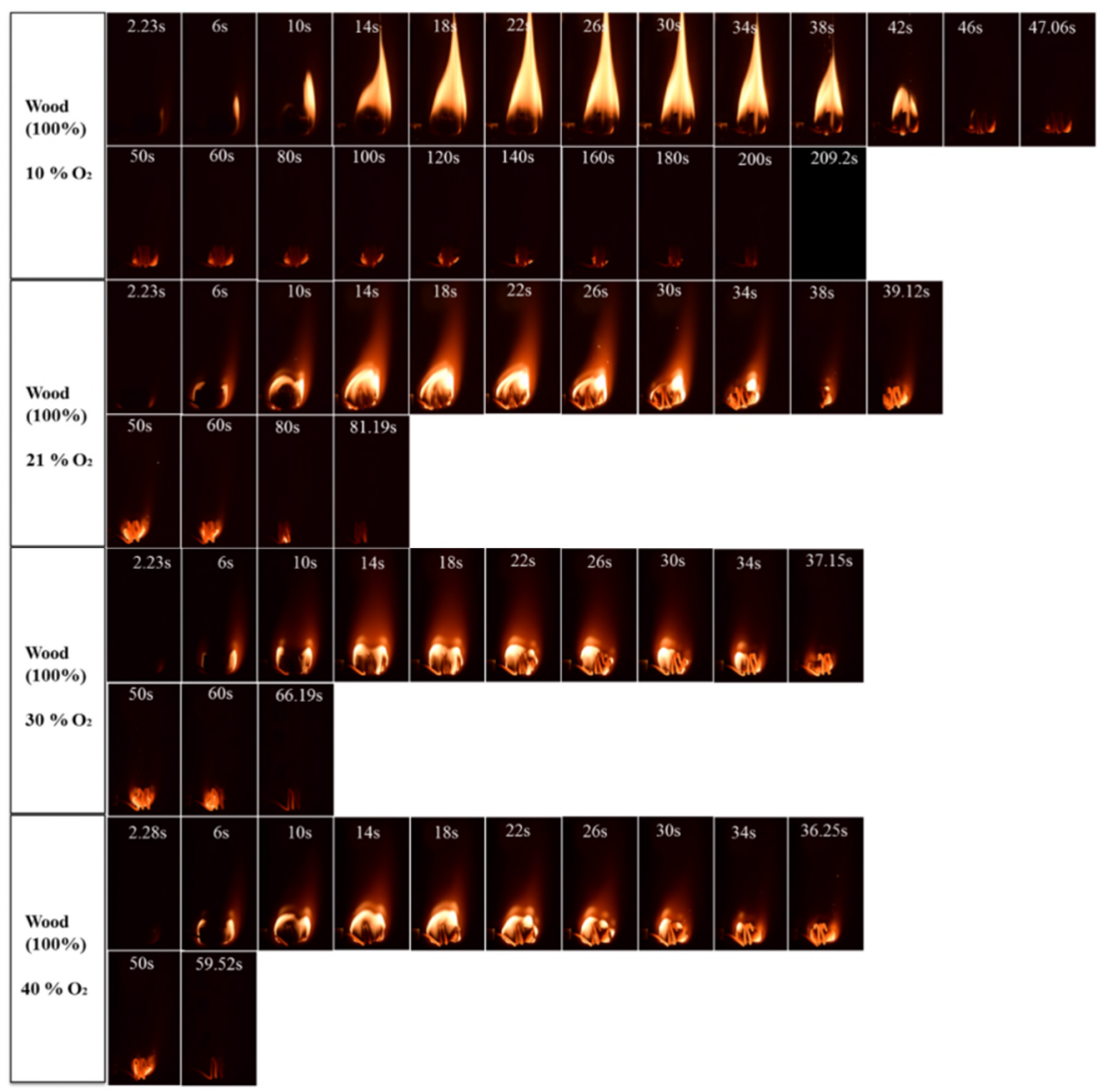

(a) 


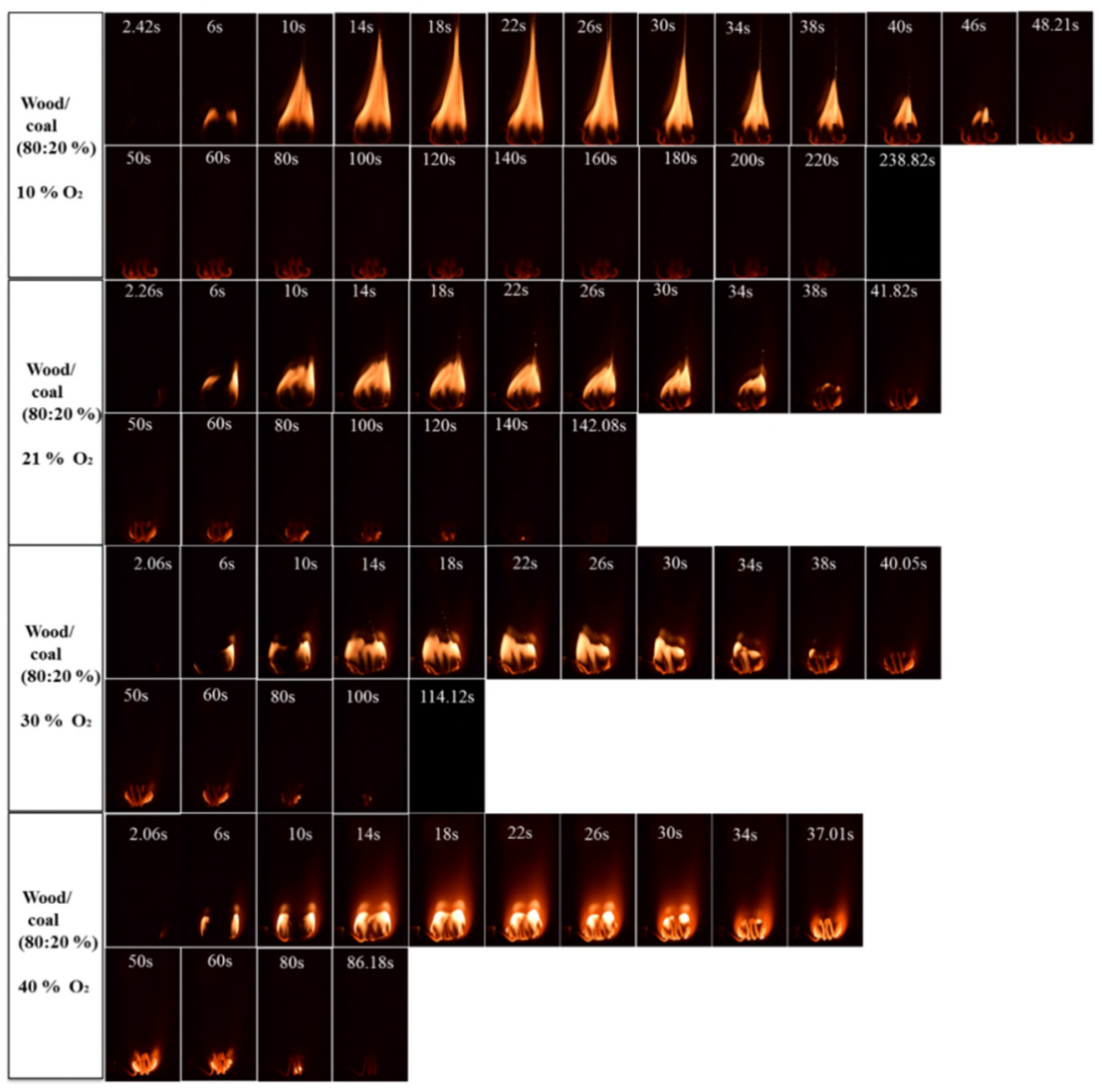

(b)

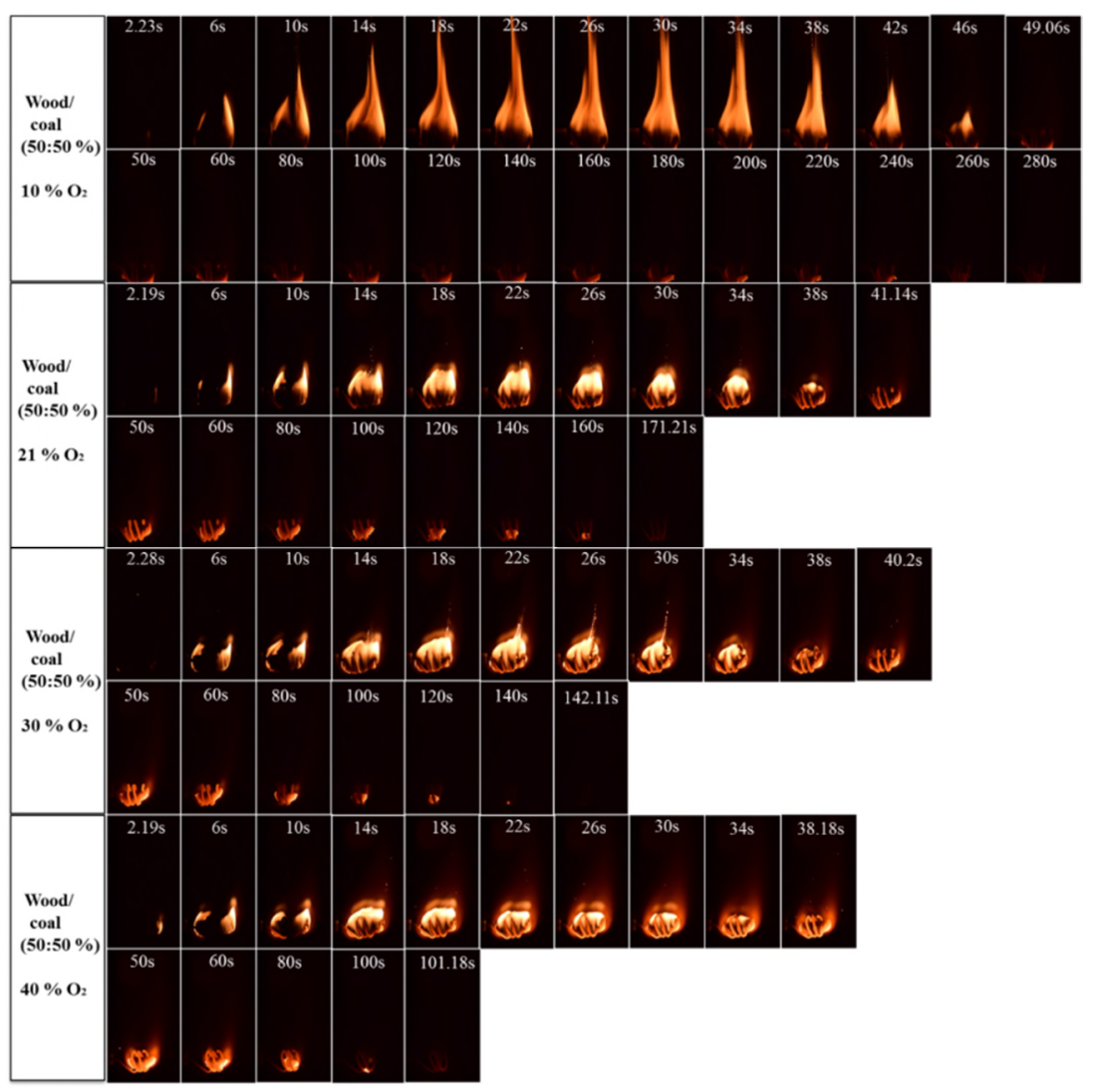

(c) 
Fig. 11. Captured images obtained from burning pellets of $40 \mathrm{~g}$ over time: (a) 100\% wood, (b) $80: 20 \%$ wood-coal and (c) 50:50\% wood-coal. The figure shows the ignition and the flame and char characteristics from the coal and wood mixtures under oxygen concentrations of $10 \%$ $40 \%$.

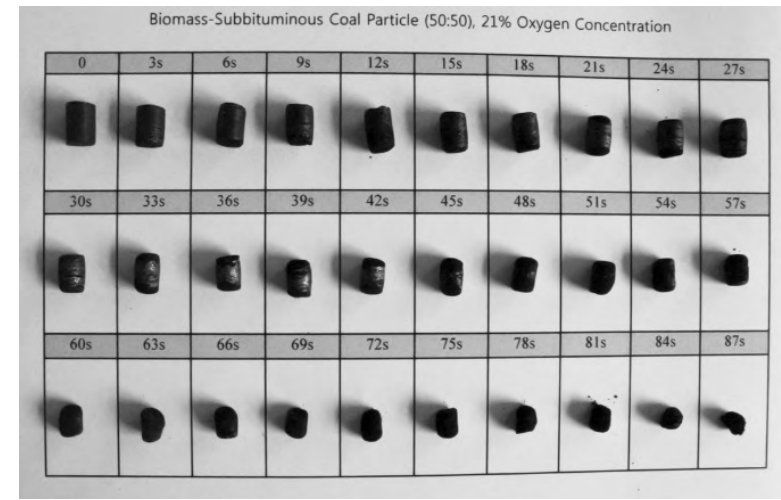

(a) $21 \% \mathrm{O}_{2}$

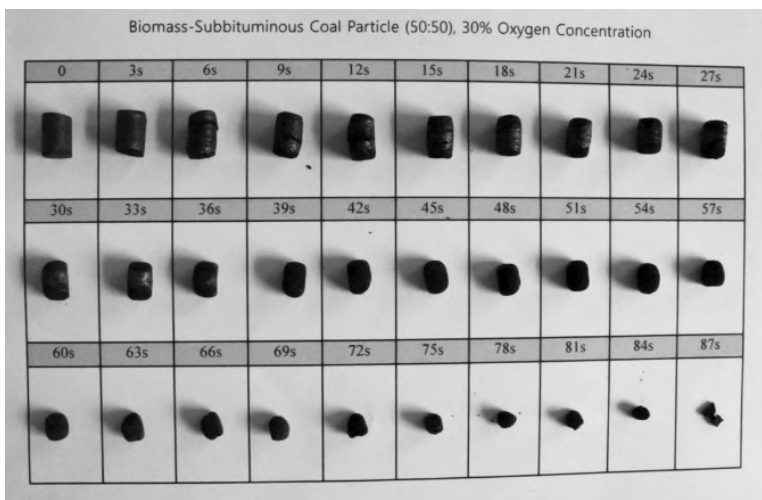

(b) $30 \% \mathrm{O}_{2}$

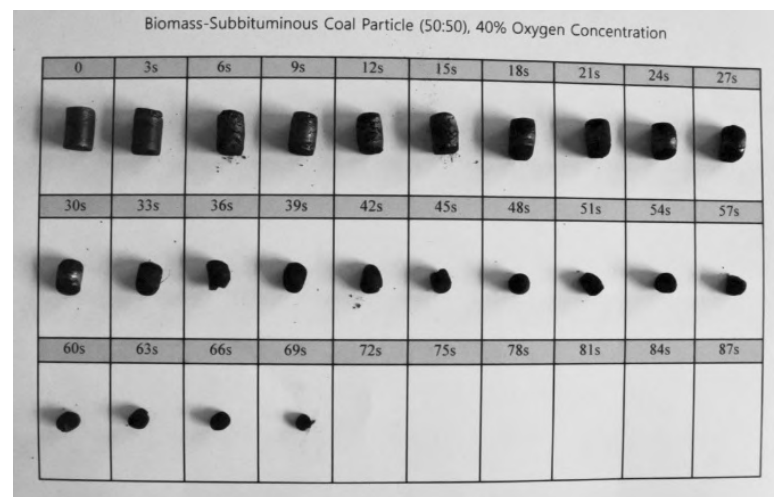

(c) $40 \% \mathrm{O}_{2}$

Fig. 12. Particle volume change from heating to char combustion under different oxygen concentrations: these particles are $50: 50 \%$ of biomass and coal where the mass was kept identical at $0.27 \mathrm{~g}$. The figure shows that the volume of the particle also decreased during volatile combustion. 


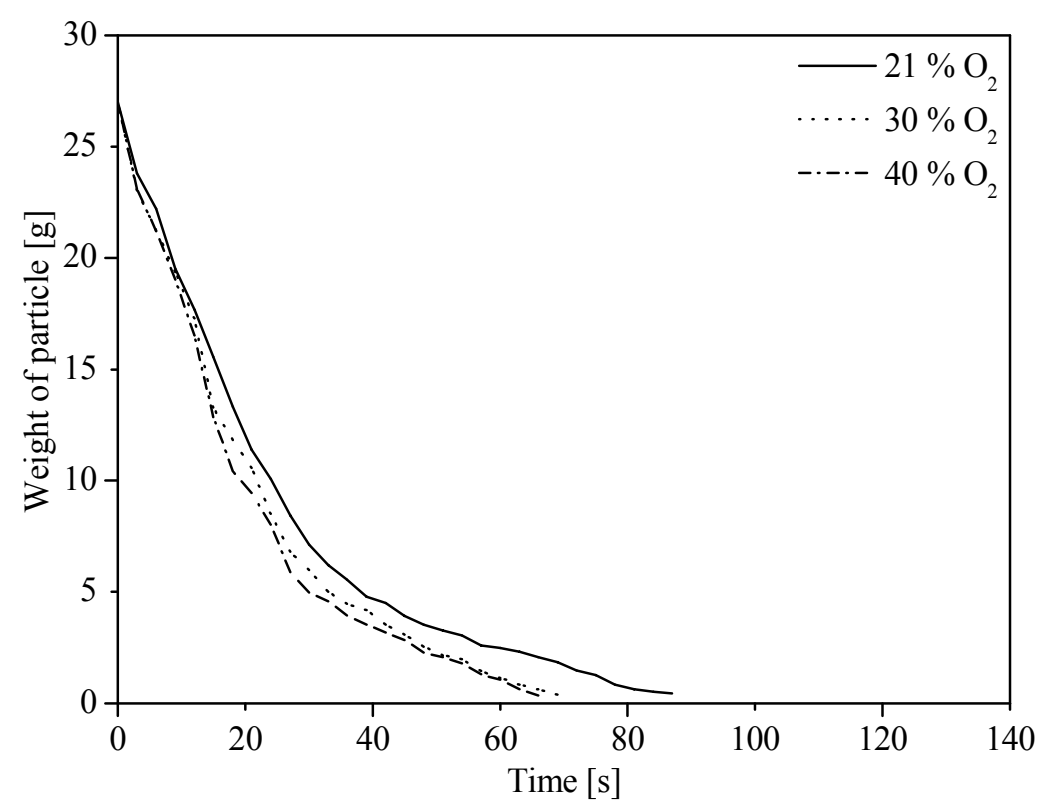

(a) $80: 20$

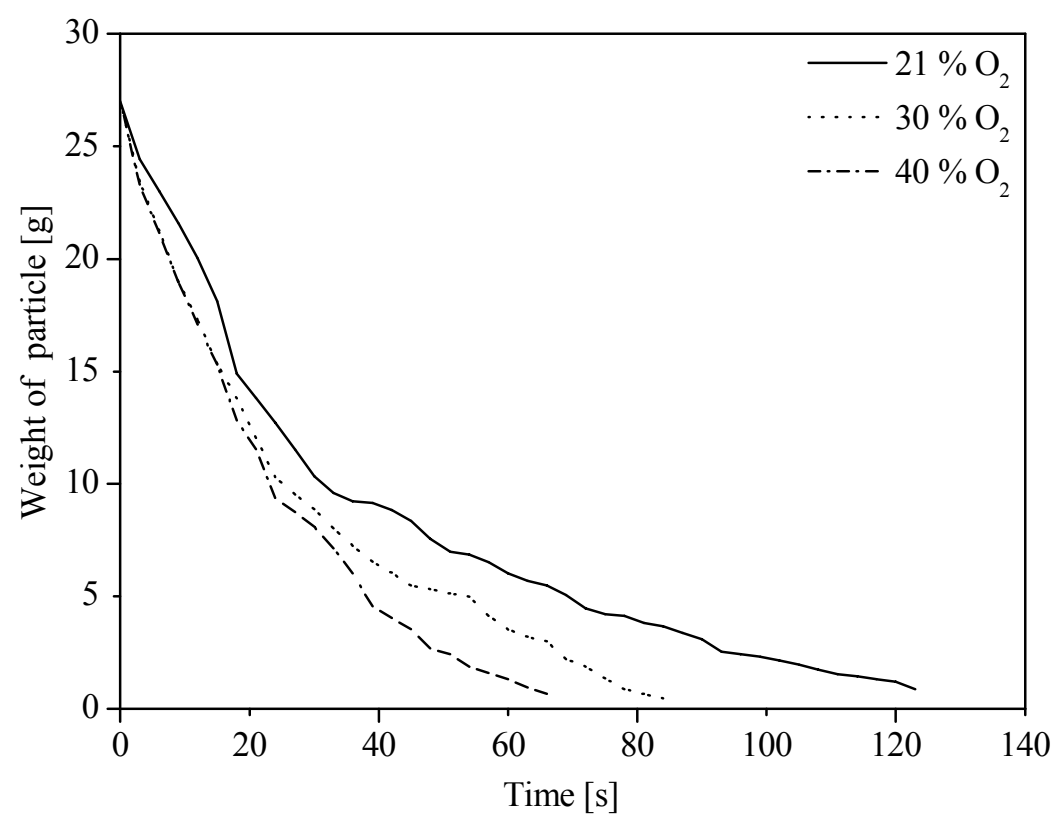

(b) $50: 50$

Fig. 13. Reduction of particle weight for 80:20 biomass-coal and 50:50 biomass-coal pellets at rapid heating rates and under $21 \%-40 \%$ oxygen concentrations. The results present the tendency for different mass reduction from a mixture of fuels. 


\section{Conclusions}

The combustion characteristics of single pellets of different coal and wood mixtures were experimentally investigated for co-firing in a laboratory EFR. Comparisons of combustion times and physical changes in the volatile flame and char particle were analysed over time. To approach the feasible burning behaviours in a realistic furnace, all the pellets were ignited at rapid heating rates, which affected the fast thermal decomposition of hemicellulose, cellulose and lignin. The reduction of the pellet weight and particle shrinkage were also measured. From direct observation methods, the modes of the volatile flame and overlapping combustion were discussed for the different biomass-coal mixture pellets for co-firing. The conclusions of this experimental study are as follows:

1. The volatile combustion times between the three pellets were not significantly different, but the char burn-out times increased noticeably as the coal mixture increased because of the increase in the fixed carbon content and the relatively slower coal char oxidation

2. Two types of volatile flame, i.e. partially detached and diffusion flame, were clearly distinguished during homogeneous combustion. The partially detached flame was observed on the pure biomass pellet at over $21 \%$ oxygen concentration and on the biomass pellets with coal mixtures at $40 \%$ oxygen concentration. This was attributed to the fast devolatilisation rate in biomass materials or the high oxygen diffusion rate.

3. During volatile combustion, the pellets shrank by $26.3 \%-37.5 \%$ because of the char oxidation in the early stage and the rapid release of volatile matter. The biomass char particle had the highest luminosity owing it to high char reactivity.

4. The ignition time was shorter as the aspect ratio of the burning pellets with identical diameter increased, which can result in a dramatic increase of the temperature at the 
particle surface, where overlapping combustion was more pronounced.

5. The pellet mass reduction rate of 50:50 biomass-coal pellets increased with increasing oxygen concentration, but the weight loss of different size pellets was similar for $40 \%$ oxygen, where fragmentation occurred primarily at the particle surface.

\section{Acknowledgements}

This work was supported by the International Energy Joint R\&D Program of the Korea Institute of Energy Technology Evaluation and Planning (KETEP) grant, funded by the Korea Government Ministry of Trade, Industry, and Energy (Project No. 20161110100090). Furthermore, we thank Hyemin Park and Solbi Choi (KITECH), who actively contributed to the sample preparation. 


\section{References}

(1) Nussbaumer, T., Combustion and Co-combustion of Biomass: Fundamentals, Technologies, and Primary Measures for Emission Reduction. Energy \& Fuels 2003, 17 (6), 1510-1521.

(2) Lu H., Baxter L. (2011) Biomass Combustion Characteristics and Implications for Renewable Energy. In: Grammelis P. (eds) Solid Biofuels for Energy. Green Energy and Technology. Springer, London.

(3) Dornburg, V.; Faaij, A. P. C., Efficiency and economy of wood-fired biomass energy systems in relation to scale regarding heat and power generation using combustion and gasification technologies. Biomass and Bioenergy 2001, 21 (2), 91-108.

(4) Parikka, M., Global biomass fuel resources. Biomass and Bioenergy 2004, 27 (6), 613620.

(5) Demirbas, A., Combustion characteristics of different biomass fuels. Progress in Energy and Combustion Science 2004, 30 (2), 219-230.

(6) Jenkins, B. M.; Baxter, L. L.; Miles, T. R.; Miles, T. R., Combustion properties of biomass. Fuel Processing Technology 1998, 54 (1), 17-46.

(7) Baxter, L., Biomass-coal co-combustion: opportunity for affordable renewable energy. Fuel 2005, 84 (10), 1295-1302.

(8) Robinson, A. L.; Rhodes, J. S.; Keith, D. W., Assessment of Potential Carbon Dioxide Reductions Due to Biomass-Coal Cofiring in the United States. Environmental Science \& Technology 2003, 37 (22), 5081-5089.

(9) Snelling, D. R.; Thomson, K. A.; Smallwood, G. J.; Oslash; G-uacute, L.; lder; Weckman, E. J.; Fraser, R. A., Spectrally Resolved Measurement of Flame Radiation to Determine Soot Temperature and Concentration. AIAA Journal 2002, 40 (9), 1789-1795.

(10) Andersson, K.; Johansson, R.; Johnsson, F.; Leckner, B., Radiation Intensity of Propane- 
Fired Oxy-Fuel Flames: Implications for Soot Formation. Energy \& Fuels 2008, 22 (3), $1535-1541$.

(11) Spliethoff, H.; Hein, K. R. G., Effect of co-combustion of biomass on emissions in pulverized fuel furnaces. Fuel Processing Technology 1998, 54 (1), 189-205.

(12) Tillman, D. A., Biomass cofiring: the technology, the experience, the combustion consequences. Biomass and Bioenergy 2000, 19 (6), 365-384.

(13) Sahu, S. G.; Chakraborty, N.; Sarkar, P., Coal-biomass co-combustion: An overview. Renewable and Sustainable Energy Reviews 2014, 39, 575-586.

(14) Otero, M.; Sánchez, M. E.; Gómez, X., Co-firing of coal and manure biomass: A TG-MS approach. Bioresource Technology 2011, 102 (17), 8304-8309.

(15) Chen, W.-H.; Wu, J.-S., An evaluation on rice husks and pulverized coal blends using a drop tube furnace and a thermogravimetric analyzer for application to a blast furnace. Energy 2009, 34 (10), 1458-1466.

(16) Wu, H.; Glarborg, P.; Frandsen, F. J.; Dam-Johansen, K.; Jensen, P. A.; Sander, B., Cocombustion of pulverized coal and solid recovered fuel in an entrained flow reactor General combustion and ash behaviour. Fuel 2011, 90 (5), 1980-1991.

(17) Mock, C.; Lee, H.; Choi, S.; Yang, W.; Manovic, V., Burning characteristics of single particles of coal and wood mixtures for co-firing in an upward-flowing hot gas stream. Fuel Processing Technology 2017, 163, 20-34.

(18) Gilbert, P.; Ryu, C.; Sharifi, V.; Swithenbank, J., Effect of process parameters on pelletisation of herbaceous crops. Fuel 2009, 88 (8), 1491-1497.

(19) Lehtikangas, P., Storage effects on pelletised sawdust, logging residues and bark. Biomass and Bioenergy 2000, 19 (5), 287-293.

(20) Pettersson, A.; Zevenhoven, M.; Steenari, B.-M.; Åmand, L.-E., Application of chemical fractionation methods for characterisation of biofuels, waste derived fuels and CFB co- 
combustion fly ashes. Fuel 2008, 87 (15), 3183-3193.

(21) Yin, C.; Rosendahl, L. A.; Kær, S. K., Grate-firing of biomass for heat and power production. Progress in Energy and Combustion Science 2008, 34 (6), 725-754.

(22) Shan, F.; Lin, Q.; Zhou, K.; Wu, Y.; Fu, W.; Zhang, P.; Song, L.; Shao, C.; Yi, B., An experimental study of ignition and combustion of single biomass pellets in air and oxyfuel. Fuel 2017, 188, 277-284.

(23) Isemin, R.; Mikhalev, A.; Klimov, D.; Grammelis, P.; Margaritis, N.; Kourkoumpas, D.S.; Zaichenko, V., Torrefaction and combustion of pellets made of a mixture of coal sludge and straw. Fuel 2017, 210, 859-865.

(24) Tsuchiya, Y.; Yoshida, T., Pelletization of brown coal and rice bran in Indonesia: Characteristics of the mixture pellets including safety during transportation. Fuel Processing Technology 2017, 156, 68-71.

(25) Seepana, S.; Arumugam, S.; Sivaramakrishnan, K.; Muthukrishnan, M., Evaluation of feasibility of pelletized wood co-firing with high ash Indian coals. Journal of the Energy Institute 2017, in press, doi.org/10.1016/j.joei.2017.12.003.

(26) Biagini, E.; Lippi, F.; Petarca, L.; Tognotti, L., Devolatilization rate of biomasses and coal-biomass blends: an experimental investigation. Fuel 2002, 81 (8), 1041-1050.

(27) Wang, G.; Zhang, J.; Shao, J.; Liu, Z.; Zhang, G.; Xu, T.; Guo, J.; Wang, H.; Xu, R.; Lin, H., Thermal behavior and kinetic analysis of co-combustion of waste biomass/low rank coal blends. Energy Conversion and Management 2016, 124, 414-426.

(28) Moon, C.; Sung, Y.; Ahn, S.; Kim, T.; Choi, G.; Kim, D., Effect of blending ratio on combustion performance in blends of biomass and coals of different ranks. Experimental Thermal and Fluid Science 2013, 47, 232-240.

(29) Flower, M.; Gibbins, J., A radiant heating wire mesh single-particle biomass combustion apparatus. Fuel 2009, 88 (12), 2418-2427. 
(30) Momeni, M.; Yin, C.; Kær, S. K.; Hansen, T. B.; Jensen, P. A.; Glarborg, P., Experimental Study on Effects of Particle Shape and Operating Conditions on Combustion Characteristics of Single Biomass Particles. Energy \& Fuels 2013, 27 (1), 507-514.

(31) Mason, P. E.; Darvell, L. I.; Jones, J. M.; Pourkashanian, M.; Williams, A., Single particle flame-combustion studies on solid biomass fuels. Fuel 2015, 151, 21-30.

(32) Mock, C.; Lee, H.; Choi, S.; Manovic, V., Flame structures and ignition characteristics of torrefied and raw sewage sludge particles at rapid heating rates. Fuel 2017, 200, 467-480.

(33) Mock, C.; Lee, H.; Choi, S.; Manovic, V., Combustion Behavior of Relatively Large Pulverized Biomass Particles at Rapid Heating Rates. Energy \& Fuels 2016, 30 (12), 10809-10822.

(34) Yang, H.; Yan, R.; Chen, H.; Lee, D. H.; Zheng, C., Characteristics of hemicellulose, cellulose and lignin pyrolysis. Fuel 2007, 86 (12), 1781-1788.

(35) Yeo, J. Y.; Chin, B. L. F.; Tan, J. K.; Loh, Y. S., Comparative studies on the pyrolysis of cellulose, hemicellulose, and lignin based on combined kinetics. Journal of the Energy Institute 2017.

(36) Burhenne, L.; Messmer, J.; Aicher, T.; Laborie, M.-P., The effect of the biomass components lignin, cellulose and hemicellulose on TGA and fixed bed pyrolysis. Journal of Analytical and Applied Pyrolysis 2013, 101, 177-184.

(37) Yu, J.; Paterson, N.; Blamey, J.; Millan, M., Cellulose, xylan and lignin interactions during pyrolysis of lignocellulosic biomass. Fuel 2017, 191, 140-149.

(38) Dorez, G.; Ferry, L.; Sonnier, R.; Taguet, A.; Lopez-Cuesta, J. M., Effect of cellulose, hemicellulose and lignin contents on pyrolysis and combustion of natural fibers. Journal of Analytical and Applied Pyrolysis 2014, 107, 323-331.

(39) Gurgel Veras, C. A.; Saastamoinen, J.; Carvalho Jr, J. A.; Aho, M., Overlapping of the devolatilization and char combustion stages in the burning of coal particles. Combustion 
and Flame 1999, $116(4), 567-579$.

(40) Timothy, L. D.; Sarofim, A. F.; Béer, J. M., Characteristics of single particle coal combustion. Symposium (International) on Combustion 1982, 19 (1), 1123-1130.

(41) Chun Wai, L.; Niksa, S., The combustion of individual particles of various coal types. Combustion and Flame 1992, 90 (1), 45-70.

(42) Khatami, R.; Stivers, C.; Joshi, K.; Levendis, Y. A.; Sarofim, A. F., Combustion behavior of single particles from three different coal ranks and from sugar cane bagasse in $\mathrm{O} 2 / \mathrm{N} 2$ and $\mathrm{O} 2 / \mathrm{CO} 2$ atmospheres. Combustion and Flame 2012, 159 (3), 1253-1271.

(43) Lee, H.; Choi, S., An observation of combustion behavior of a single coal particle entrained into hot gas flow. Combustion and Flame 2015, 162 (6), 2610-2620.

(44) Wornat, M. J.; Hurt, R. H.; Davis, K. A.; Yang, N. Y. C., Single-particle combustion of two biomass chars. Symposium (International) on Combustion 1996, 26 (2), 3075-3083.

(45) Yang, Y. B.; Sharifi, V. N.; Swithenbank, J.; Ma, L.; Darvell, L. I.; Jones, J. M.; Pourkashanian, M.; Williams, A., Combustion of a Single Particle of Biomass. Energy \& Fuels 2008, 22 (1), 306-316.

(46) Fletcher, T. H.; Ma, J.; Rigby, J. R.; Brown, A. L.; Webb, B. W., Soot in coal combustion systems. Progress in Energy and Combustion Science 1997, 23 (3), 283-301. 